\title{
Levantamiento del velo y Derecho Administrativo privado en el ámbito de la Administración Local
}

\author{
Santiago González-Varas Ibáñez \\ Profesor Titular de Derecho Administrativo de \\ la Universidad de León
}

«El que huye ha de combatir nuevamente», DEMÓSTENES

\begin{abstract}
Sumario: PLANTEAMIENTO. PRIMERA PARTE INTRODUCTORIA. PRINCIPIOS RECTORES DE LA ACTIVIDAD ECONÓMICA LOCAL. I. LA LIBRE INICIATIVA ECONÓMICA DE LA ADMINISTRACIÓN LOCAL. II. LA POTESTAD DE LIBRE ORGANIZACIÓN DE LOS SERVICIOS PÚBLICOS. A. La «elección» entre el régimen de monopolio y de competencia. B. La libertad de organización del servicio público entre formas directas e indirectas de gestión. C. La lifoertad de elección entre formas públicas y privadas de gestión de los servicios públicos locales. SEGUNDA PARTE: EL PROBLEMA JURÍDICO: LOS POSIBLES FRAUDES DE LEY Y ABUSOS DE DERECHO. I. PLANTEAMIENTO. II. LAS RESPUESTAS JURÍDICAS QUE SE PLANTEAN (I): EL DERECHO DE LA COMPETENCIA Y SUS LIMITACIONES. III. LA TEORÍA DEL LEVANTAMIENTO DEL VELO COMO PARTE DEL DERECHO ADMINISTRATIVO PRIVADO. A. La doctrina del levantamiento del velo en el Derecho civil español. B. La teoría del levantamiento del velo como parte del Derecho administrativo privado. C. Levantamiento del velo en el Derecho administrativo español. D. El problema de la jurisdicción competente. E. El Derecho administrativo privado y las sociedades de Derecho privado de capital mayoritariamente público (del artículo 155.2 de la Ley de contratos). TERCERA PARTE: EL PROBLEMA DE LA SUJECIÓN A DERECHO DE LA ACTIVIDAD AD EXTRA DE LA FORMA DE GESTIÓN DEL SERVICIO PÚBLICO. I. EL «PROBLEMA» Y EL DERECHO ADMINISTRATIVO PRIVADO. II. LA TEORÍA DE LOS ACTOS SEPARABLES. III. EL DERECHO DE LA COMPETENCIA EN RELACIÓN CON EL PROBLEMA DE LA SUJECIÓN A DERECHO DE LA ACTIVIDAD DE LAS EMPRESAS PÚBLICAS LOCALES. IV. LOS CRITERIOS FUNCIONALES. BIBLIOGRAFIA EMPLEADA.
\end{abstract}

\section{PLANTEAMIENTO}

El presente trabajo estudia la aplicación de las teorías del levantamiento del velo y del Derecho administrativo privado en el ámbito de la Administración local.

Una primera parte, introductoria, menciona las facultades y límites que se derivan del ejercicio de las potestades que el ordenamiento otorga a la Admi- 
nistración local para el desempeño o realización de funciones económicas y prestacionales («libre iniciativa para el desarrollo de actuaciones»; «libre elección de la forma de organización del servicio público»; «libre elección en favor del Derecho privado como Derecho regulador de la entidad que gestiona el servicio») '.

En segundo lugar, se analizan los problemas jurídicos a los que conduce el ejercicio de dichas potestades. Precisamente, en relación con dichos problemas se estudiará y propugnará acto seguido la aplicación de la teoría del levantamiento del velo y del Derecho administrativo privado.

\section{PRIMERA PARTE INTRODUCTORIA. PRINCIPIOS RECTORES DE LA ACTIVIDAD ECONÓMICA LOCAL}

\section{LA LIBRE INICIATIVA ECONÓMICA DE LA ADMINISTRACIÓN LOCAL}

La Constitución y la legislación local dejan bien clara la libre iniciativa económica local, en virtud del artículo 128.2 de la Constitución ${ }^{2}$, y los artículos 86 de la LBRL ${ }^{3}$ y 96 del Texto Refundido ${ }^{4}$, en consonancia, por otra parte, con el principio de autonomía local ${ }^{\mathrm{s}}$. Y esta libre iniciativa económica abarca

\footnotetext{
1 En este sentido, el artículo 30 del RSCL reconoce la potestad de libre constitución y configuración de los servicios, pero a continuación (artículo 32) se afirma que «la prestación de los servicios se atemperará a las normas que rijan cada uno de ellos». Por su parte, la STS de 13 de octubre de 1986 (Ar. 6420), el Ayuntamiento tiene una «evidente potestad de poder organizar, modificar o reorganizar la forma de prestación del servicio del modo que el interés público demande, pero respetando siempre las normas de procedimiento que se han señalado y sin perjuicio de los deberes de aquél».

2 Sin olvidar la «intervención de empresas cuando así lo exigiere el interés general», que también prevé el artículo 128.2 de la CE. Según la STS de 29 de marzo de 1996 (Ar. 2818), la Administración local no puede intervenir la actividad objeto de litigio, ya que esta facultad establecida en el artículo 128 de la CE presupone una Ley, y ya que no existe una situación de emergencia. Véase, por todos, la monografía sobre el tema de E. GAMERo CASADo, La intervención..., págs. 51 y ss.

3 Recuérdese el texto del artículo 86 de la LBRL (Ley de Bases de Régimen Local, 7/1985, de 2 de abril): «Las Entidades Locales, mediante expediente acreditativo de la conveniencia y oportunidad de la medida, podrán ejercer la iniciativa pública para el ejercicio de actividades económicas, conforme al artículo 128.2 de la Constitución".

4 A cuyo tenor, «la iniciativa de las Entidades Locales para el ejercicio de actividades económicas, cuando lo sea en régimen de libre concurrencia, podrá recaer sobre cualquier tipo de actividad que sea de utilidad pública y se preste dentro del término municipal y en beneficio de sus habitantes".
}

5 De este principio de autonomía local puede también hacerse desprender la necesidad de evitar la intromisión de otras Administraciones en la toma de decisiones de la Administración local. 
LEVANTAMIENTO DEL VELO Y DERECHO ADMINISTRATIVO ...

tanto las actividades prestacionales o serviciales como las propiamente económicas, mercantiles o de carácter meramente industrial ${ }^{6}$.

En relación con los límites (que pueden hacerse corresponder con el principio constitucional de la libertad de empresa) ${ }^{7}$, las actuaciones económicas se condicionan a la presencia de «utilidad pública» y al «desarrollo en beneficio de los habitantes» 8 .

También han de respetarse los criterios de distribución de competencias, tal como se desprende de la jurisprudencia de la jurisdicción contencioso-administrativa ${ }^{9}$. En este contexto puede también valorarse la regla contenida en el artículo 31.2 del RSCL, que viene a disponer la imposibilidad de crear un servicio público que implique la «duplicidad de servicios por otros Organismos públicos con competencia especialmente instituida para el desarrollo de los mismos» 10 .

Otro límite es la existencia de «solvencia suficiente para desempeñar la actividad económica pretendida» por parte del municipio, tal como establece la Ley Reguladora de las Haciendas Locales"

Igualmente, la actividad económica no podrá realizarse si aquélla estuviera reservada a los particulares; así lo entendió el Tribunal Supremo español en su sentencia de 28 de septiembre de $1993^{12}$, de modo que anuló las normas reglamentarias que habilitaban la actuación administrativa en el mercado ${ }^{13}$, apoyán-

6 Véase sobre esto el clásico trabajo de E. Garcla DE ENTERrfa, «La actividad...», pág. 121.

7 Véanse las STC 227/1993, de 9 de julio (BOE de 12 de agosto), 11/198I, de 8 de abril (BOE de 25 de abril), 37/1987, de 26 de marzo (BOE de 14 de abril), 88/1986, de 1 de julio (BOE de 22 de julio), 225/1983, de 8 de julio (BOE de 2 de agosto).

8 Es el artículo 96 del TR. La exigencia de tales requisitos («utilidad pública» y «desarrollo en beneficio de los habitantes del municipio») sirve por otra parte para impedir el ánimo lucrativo en la actuación económica municipal. En el Derecho comparado el artículo 89.2 de la Ley bávara dice que «los municipios sólo pueden crear, asumir o ampliar empresas si lo justifica un interés público». La Ley de Nordrhein-Westfalen exige «un interés público de urgente resarcimiento».

9 Por ejemplo, la Sentencia del Tribunal Supremo de 16 de septiembre de 1993 (Sala 3.") Ar. 6530. En el Derecho comparado puede verse la sentencia del Tribunal Constitucional alemán, publicada en BVerfGE 12, pág. 205.

10 Véase también el artículo 50 del RSCL.

It Véanse, asimismo, las STC 57/1983, de 28 de junio (BOE de 15 de julio) y 179/1985, de 19 de diciembre (BOE de 15 de enero de 1986).

12 Sala 3:", Ar. 6542.

13 Artículo 12.f del Reglamento de Funcionamiento del Servicio de Mayorista de Pescados de Valencia (de 12 de marzo de 1987). 
dose en criterios tales como la «sana concurrencia comercial» y la necesidad de «asegurar en materia de abastos la libre competencia», de los cuales el tribunal dedujo que los mercados mayoristas debían realizarse en régimen de libre competencia sin intervención administrativa.

En el Derecho español se entiende mayoritariamente que no rige el principio de «subsidiariedad» (sino el de «compatibilidad» entre la actividad pública y privada, pudiéndose aquélla desarrollar aun cuando ésta fuera posible). Este hecho acentúa entonces la necesidad de establecer criterios jurídicos que rijan dicha iniciativa pública local («conveniencia y oportunidad», «utilidad pública», «desarrollo en beneficio de los habitantes del municipio») ${ }^{14}$.

Además, para poder iniciar una actividad económica ha de seguirse un procedimiento, cuya importancia radica en gran parte en la afirmación de una garantía de motivación (a través de la necesidad de acreditar la conveniencia y oportunidad de la actividad) ${ }^{15}$ y en el reconocimiento de un trámite de alegaciones (que concede la oportunidad de alegar en contra de la actividad pretendida). Doctrinalmente, se ha defendido que el procedimiento sólo es necesario cuando se trate de actividades de carácter mercantil pero no es preciso para las actividades prestacionales o serviciales que se realicen en régimen de competencia ${ }^{16}$; sin embargo, puede ser interesante insistir en la necesidad de seguir un procedimiento también respecto de la gestión de servicios públicos locales (el artículo 97.1 del TR dispone la obligación de que la Administración «determine la forma de gestión») a fin de articular o facilitar un control judicial sobre la toma de decisiones relativas a la forma de gestión del servicio ${ }^{17}$.

14 Es discutible hasta qué punto la aplicación de estos principios no conduce, si no ya a una regla de subsidiariedad, sí a un "principio de preferencia» de la actividad económica de los ciudadanos frente a la de las Administración Públicas. Asimismo, debe tenerse en cuenta el artículo 45.2 del RSCL, a cuyo tenor la municipalización tenderá a conseguir que la prestación del servicio reporte a los usuarios condiciones más ventajosas que las que pudiera ofrecerles la iniciativa particular y la gestión directa (y en esta línea véase el artículo 98.2 del RSCL). Es significativo considerar que en el Derecho alemán, de postulados jurídicos similares a los del Derecho español se hace desprender el principio de subsidiariedad en el ámbito económico local, regla que se proclama en la legislación local, por ejemplo en el artículo 108.1 de la Ley municipal de Niedersachsen: «para que la actuación económica pueda desarrollarse, ésta no ha de poder realizarse satisfactoriamente por un empresario privado". Este principio de subsidiariedad está tradicionalmente consagrado en el artículo 67 de de la Ley Municipal alemana - de 30 de enero de 1935 - $R G B I I$, pág. 49 y se defiende mayoritariamențe por la doctrina.

15 Artículo 86.1 de la LBRL; artículo 97.1 del TR, para el procedimiento. Un análisis desmenuzado sobre el procedimiento que han de seguir las Entidades locales, puede verse por todos F. SOSA WAGNER, La gestión..., pág. 46.

16 J. M. Dlaz Lema, Los monopolios..., pág. 88; F. LLISET Borrel, La actividad..., pág. 26. Se parte de que los servicios públicos tienen habilitación legal concreta, y que incluso pueden llegar a tener carácter obligatorio (artículo 26 LBRL).

17 Desde este punto de vista puede verse también el artículo 33 del RSCL a cuyo tenor, «las Corpora- 
LEVANTAMIENTO DEL VELO Y DERECHO ADMINISTRATIVO ...

Finalmente, si la actuación de la Corporación pretende ser monopolística, el artículo 97.2.2 del Texto Refundido condiciona tal posibilidad a la aprobación del acuerdo de la Corporación por parte del Consejo de Gobierno de la Comunidad Autónoma correspondiente ${ }^{18}$. Esto hace referencia, según el artículo 97.2 del Texto Refundido, a la ejecución efectiva en régimen de monopolio de «las actividades o servicios esenciales reservados de acuerdo con lo establecido en el artículo 86.3 de la LBRL» ${ }^{19}$, lista que puede ser ampliada mediante Ley (artículo 86.3 in fine del primer párrafo). La intervención de la Comunidad Autónoma se agota al momento de «establecer el régimen del monopolio» pero no puede alcanzar a «las distintas actuaciones producidas en su desarrollo», de acuerdo con los artículos 86.3 y 107 de la LBRL y el artículo 148 del RSCL ${ }^{20}$.

Por otra parte, la municipalización con monopolio ha de respetar el principio de igualdad, extremo éste sobre el que insiste la jurisprudencia cuando por ejemplo sienta que si la monopolización implica una expropiación la Administración no puede declarar sin justificación que unas determinadas empresas son expropiables y otras no ${ }^{2 !}$.

\section{LA POTESTAD DE LIBBRE ORGANIZACIÓN DE LOS SERVICIOS PÚBLICOS}

En el Derecho español, «las Corporaciones locales tienen plena potestad para constituir, modificar y suprimir los servicios de su competencia, tanto en el orden personal como en el económico o en cualesquiera otros aspectos» ${ }^{22}$.

ciones locales determinarán, en la reglamentación de todo servicio que establezcan, las modalidades de prestación (...)" así como la entidad que asume la prestación del servicio. Véase también el artículo 42 del RSCL.

18 La necesidad de seguir un procedimiento (municipalizador) se ha visto tradicionalmente como la garantía a favor de los particulares al respecto de tales municipalizaciones (STS de 21 de julio de 1987, Ar. 7549). Sobre el procedimiento, artículos 56 y ss. del RSCL.

19 En concreto son el abastecimiento y depuración de aguas, la recogida, tratamiento y aprovechamiento de residuos, el suministro de gas y calefacción, los mataderos, mercados y lonjas centrales, el transporte público y de viajeros.

20 Así, la fijación de los precios o tarifas: STS de 3 de mayo de 1996 (Sala 3.'), Ar. 4282; ST’S de 26 de junio de 1996 (Sala 3."), Ar. 7244.

21 Véase la STC 50/1991, de 11 de marzo y la STS de 9 de junio de 1988, Sala 3.: Ar. 4555, sobre el mismo asunto. La cuestión hace referencia al artículo 99 del TR y los artículos 51 y 52 del RSCL.

Artículo 30 del RSCL. 
Seguidamente va a estudiarse cómo se articula este principio de libertad de organización de los servicios públicos, tanto a la hora de escoger una forma directa 0 indirecta de gestión ${ }^{23}$ como a la hora de decidir por su gestión en régimen de monopolio o de libre competencia. Contra esta libertad de organización del servicio público no pueden oponerse principios tales como la libertad de empresa o los derechos adquiridos ${ }^{24}$, sin perjuicio de que los jueces habrán de comprobar en el caso concreto si las disposiciones de ordenación del servicio público lesionan algún derecho ${ }^{25}$ y se ajustan al ordenamiento jurídico. En definitiva, dicha «potestad» arraiga en la propia filosofía del servicio público: arbitrar amplias facultades a favor de los poderes públicos titulares del servicio con el fin de dejar a cubierto la satisfacción de las necesidades básicas de la población ${ }^{26}$.

\section{A. La «elección» entre el régimen de monopolio y de competencia}

El Derecho administrativo establece unos marcos dentro de los que ha de moverse la decisión administrativa que establece la gestión de los servicios en régimen de libre concurrencia o de monopolio. Concretamente, el monopolio es posible sólo en relación con las actividades o servicios esenciales, que reserva en favor de las Entidades locales el artículo 86.3 de la LBRL ${ }^{27}$, en realidad o en el fondo porque el sistema general o normal de actuación económica es la libre competencia, tal como corrobora la jurisprudencia ${ }^{28}$ y deja deducir la le-

23 Veáse la STS de 10 de julio de 1985, Ar. 3895; STS de 13 de octubre de 1986, Ar. 6420.

24 STS de 6 de junio de 1993, Ar. 6386.

25 STS de 7 de octubre de 1995, AA 1996-2 § 353: «el establecimiento de nuevas líneas interurbanas de transporte no lesiona los derechos ni el patrimonio de una empresa concesionaria».

26 Se trata de un postulado básico de la teoría del servicio público (S. González-VARAS, El reto de los servicios públicos..., págs. 12 y ss.), y que en el Derecho español se plasma en el artículo 31.1 del RSCL.

27 Puede recordarse en este contexto la reforma del Real Decreto Ley $7 / 1996$, de 7 de junio, sobre medidas urgentes de carácter fiscal y de fomento y liberalización de la actividad económica, en virtud de la cual se suprime, del artículo 86.3 de la Ley de Bases de Régimen Local, la mención a «los servicios mortuorios». Consecuentemente, su artículo 22 dispone que «se liberalizará la prestación de los servicios mortuorios», sin perjuicio de que «los Ayuntamientos podrán someter a autorización la prestación de dichos servicios». El citado precepto sigue diciendo que «la autoridad tendrá carácter reglado, debiéndose precisar normativamente los requisitos necesarios para obtenerla y se concederá a todo solicitante que reúna los requisitos exigidos y acredite disponer de los medios materiales necesarios para efectuar el transporte de cadáveres». Sobre esta reforma, por todos, E. MOREU CARBonell en Revista Aragonesa de Administración Pública, n. ${ }^{\circ}$ 10, 1997, pág. 603.

28

En este contexto puede citarse la STS de 7 de mayo de 1987, Sala 4., Ar. 5246. Entre otros razonamientos, apunta: «el principio de libre concurrencia, en vez de encerrarse en limitaciones y obstáculos, debe abrirse y facilitar las expectativas de nuevos competidores, todo ello, repetimos, en beneficio del público". Este fallo reaccionó contra la decisión del Ayuntamiento de no aumentar el número de mayoris- 
gislación (artículos 45.2, 47.2, 98.2 del RSCL y 86.3 de la LBRL). Además, la Administración Local tiene una «facultad no una obligación» respecto del monopolio, pues nada impide para que aquélla decida gestionar el servicio en régimen de libre competencia con otros empresarios privados ${ }^{29}$.

En relación con los límites, las Corporaciones locales no parecen poderse librar del famoso Derecho comunitario de la competencia. Si bien los servicios públicos locales no fueron tema presente en la mente de los redactores del Tratado de Roma, lo cierto es que el Tribunal de Justicia de las Comunidades Europeas ha venido a dar un paso significativo hacia la aplicación del Derecho de la competencia respecto de las decisiones de organización de los servicios públicos locales. En efecto, en la sentencia de 4 de mayo de 1988 (Sentencia Corinne Bodson contra SA Pompes funèbres des régions libérées) ${ }^{30}$, el Tribunal vino a declarar que las decisiones de los Ayuntamientos no podían quedar al margen del Derecho comunitario de la competencia, ya que las empresas públicas locales no podían invocar el «cumplimiento de las prescripciones de las Corporaciones locales» con el fin de librarse de la sujeción de las reglas del Derecho comunitario de la competencia. El paso principai está dado, que es ei de poder aplicar el artículo 90.1 del Tratado de la CE a la Administración local, y, con ello, evitar que las decisiones de organización de los servicios públicos falseen la competencia. Interesa entonces conocer los criterios básicos seguidos por la jurisprudencia del Tribunal luxemburgués respecto de los monopolios en general. En primer lugar, el Derecho de la competencia puede bloquear la creación o la extensión de los límites de un monopolio si ello representa un abuso de posición dominante. En segundo lugar, el Tribunal exige en todo caso una justificación objetiva para el monopolio, al partir éste de una presunción en su contra, criterios, ambos, que hemos estudiado en otro trabajo precedente ${ }^{31}$.

tas, manteniendo los puestos existentes, hecho que constituía a juicio del Tribunal un monopolio injustificado.

\footnotetext{
29 Véanse, asimismo, los artículos 96 y 112 del RSCL, en este sentido.
}

30 Corinne Bodson contra SA Pompes funèbres des régions libérées, asunto 30/87, Rec. págs. 2.479 y ss.; el origen de este supuesto estaba en la realización de tales prestaciones por una empresa ajena al monopolio existente (Bodson), lo que llevó a recurrir a las empresas monopolísticas frente a tal intromisión en el área de su esfera de gestión. La Corte de casación francesa elevó una cuestión prejudicial al Tribunal de Justicia sobre la compatibilidad de dicho monopolio con el Derecho de la competencia. Sobre los criterios, amplios, que maneja el Tribunal para considerar la «incidencia comunitaria» de una actividad desarrollada dentro de un Estado miembro pueden verse las Sentencias Cementhandelaren contra Comisión, Rec. 1972, pág. 977, apartado 29, y Bilger contra Jehle, Rec. 1970, pág. 127, apartados 3 a 5 .

31

S. GonZÁlez-VARAS IbÁ̃̄eZ, El Derecho administrativo privado..., págs. 497 a 552. 
Logicamente, todo esto puede suscitar entusiasmos y críticas $^{32}$, y lo que interesa destacar es que estos criterios van calando en el Tribunal español de Defensa de la Competencia, y, así, la resolución de 30 de octubre de $1993^{33}$ declaró que, «si bien en el caso no concurría abuso de posición dominante la ampliación del monopolio podría en cambio dar lugar a dicho abuso de posición dominante» ${ }^{34}$.

El Derecho de la competencia merece indudablemente una mayor atención y estudio, en relación con la actividad económica de los poderes públicos. No obstante, su último alcance está aún por determinar. Y, en este sentido, no puede por otra parte obviarse que el control sobre los monopolios de las Corporaciones locales no queda al margen de la jurisdicción contencioso-administrativa. Así, aquéllas han de respetar un criterio de territorialidad, sin que pueda la Administración local prohibir el ejercicio de una actividad «que parta del Municipio (o haga escala en éste) si se dirige a otros Municipios diferentes al que monopoliza la prestación del servicio» (STS de 8 de noviembre de 1988, Sala 4.", Ar. 8796; STS de 9 de mayo de 1996, Sala 3.", Ar. 4115; STS de 27 de febrero de 1991, Sala 3. ${ }^{a}$, Ar. 1395; STS de 21 de octubre de 1988, Sala 4. ${ }^{a}$, Ar. 8031). En el fondo, lo que no es posible es la extralimitación (el abuso) en el ejercicio de las facultades de la Administración local ${ }^{35}$.

32 Dentro de la primera actitud puede encuadrarse el famoso Informe sobre la libre competencia en los servicios (junio de 1992), del Tribunal de Defensa de la Competencia español, en el cual se recomienda la supresión de los monopolios locales. Dentro de los segundos, por todos, J. WIELAND y J. HellermanN, «Das Verbot...", págs. 401 y ss.

33 Expediente 325/92 Emorvisa, Boletín Económico de ICE, n. 2393 , del 29 de noviembre al 5 de diciembre de 1993, págs. 3.399 y ss. (en relación con un caso de servicios.públicos funerarios en régimen de monopolio).

34 Concretamente, se trataba de traslados de cadáveres con destino a otras poblaciones.

35 A efectos de completar el estudio de los criterios que acaban de ser apuntados, del contencioso-administrativo, interesa saber que toda prestación del servicio local más allá del territorio municipal precisa de "los correspondientes acuerdos de los Ayuntamientos respectivos" (STS de 8 de noviembre de 1988, Sala 4.: Ar. 8796), sin perjuicio de que alguno de los elementos del servicio puede desarrollarse fuera del territorio, siempre que con ello no se «afecte a la naturaleza y contenido del servicio público», de acuerdo con el artículo 46.1.c del RSCL y la jurisprudencia contencioso-administrativa cuando dice que «no puede negarse la competencia del Ayuntamiento para regular y administrar el mercado de abastos por razón de que sus instalaciones estén materialmente situadas en otro término municipal, circunstancia que para nada afecta a la naturaleza y contenido del servicio público de que se trata, que son los que determinan la competencia indiscutible de dicho Ayuntamiento" (STS de 10 de julio de 1985, Ar. 3895).

Finalmente, desde un punto de vista procesal interesa destacar que esta jurisprudencia considera procedente en estos casos la pretensión de condena y no la pretensión de anulación: «es contrario al principio de economía procesàl decretar la nulidad de actuaciones para posibilitar la defensa del recurrente»" (también la STS de 7 de mayo de 1987, Sala 4.", Ar. 5246, f.j. 3. ). 


\section{B. La libertad de organización del servicio público entre formas directas e indirectas de gestión}

El Derecho español parte de que la Corporación local es «libre» a la hora de optar entre las formas de gestión, sin estar coartada o limitada por la enumeración de las formas de gestión contenidas en el artículo 85 de la LBRL, aun a pesar de que este precepto emplee el término imperativo «adoptará» ${ }^{36}$. Sin perjuicio de ciertas limitaciones, la regla general o el punto de partida es que todos los servicios son susceptibles de ser gestionados por una forma directa $o$ indirecta de gestión (artículos 30, 70, 114.1 del RSCL), sentándose así un criterio flexible que facilita la gestión de los servicios ${ }^{37}$.

La Administración conserva la potestad de organizar el servicio más allá del momento inicial de su creación, tal como ilustra la STS de 10 de julio de 1985 (Ar. 3895) en materia de concursos de adjudicaciones de puestos en los mercados de abastos, cuando concretamente dice que «tampoco puede desconocerse la competencia municipal para la convocatoria del concurso por el hecho de que el servicio haya sido municipalizado y encomendado a la gestión de una empresa mixta, porque, como se razona extensamente en la Sentencia apelada, ello no priva a la Corporación municipal de su competencia originaria para regular y controlar la gestión del Servicio descentralizado, que es de suyo indeclinable por ser de Derecho público».

En el caso de que el servicio se gestione mediante concesión pueden ordenarse discrecionalmente las modificaciones (variación de la cantidad o calidad del servicio o la alteración de las tarifas) que aconsejare el interés público, según el artículo 127.1 del RSCL. La presencia del «interés público» ha de demostrarse, ya que se presume inexistente si «las alegaciones del Ayuntamiento

36 F. SOSA WAGNER, La gestión.... pág. 57; no es inoportuna una lectura del artículo 4.1 de la LBRL y de la Sentencia del Tribunal Constitucional de 21 de diciembre de 1989, Fundamento Jurídico Sexto.

Por otra parte, esta solución o criterio se muestra acorde con el Derecho comparado. Así, en el Derecho italiano la Ley 142/1990 (artículo 22.1) abandona el sistema enumerativo de formas de gestión (de servicios públicos) establecido en la legislación anterior (Ley 2578/1925), afirmando en cambio una potestad discrecional a favor de la Administración para definir los servicios públicos, siempre que «aquéllos tengan por objeto la producción de bienes o fines sociales o la promoción del desarrollo económico y civil de la comunidad local». Véase A. BARDusco, «Servizi locali...», págs. 28, 29, 33 y ss.

No obstante, el Derecho comparado aporta también la necesidad de fijar límites legales frente a esta libertad de elección entre las formas de gestión; buen ejemplo es el Derecho francés, ya que la Ley de 29 de enero de 1993 - Ley de prevención de la corrupción - ha extendido a la concesión administrativa las garantías propias de la contratación administrativa.

37

En este contexto puede valorarse el artículo 95 del TR, que supera la regulación del artículo 167 de la LRL según el cual la municipalización implicaba un régimen de gestión directa por la propia Administración, sin posibilidad de un concesionario interpuesto. Puede verse sobre esto, M. F. CLAVERO ARÉvalo, Municipalización..., págs. 130 y ss. 
ni siquiera razonan», o si no contradicen la «impugnación hecha en el proceso» (STS de 6 de junio de 1993, Ar. 6386).

Incidiendo en los límites, es bien conocida la regla según la cual no pueden prestarse por gestión indirecta servicios que impliquen ejercicio de autoridad (artículos 85.2 de la LBRL, 95.1 del TR y 43.1 y 69.1 del Reglamento de Servicios) ${ }^{38}$. También, la opción en favor del arrendamiento está limitada (en virtud de los artículos 95.2 del TR y 138.2 y 140.2 del RSCL), así como en favor de las formas societarias, en caso de desarrollarse la gestión por una sociedad de capital íntegra o parcialmente público ${ }^{39}$. En este sentido, en leyes especiales pueden también encontrarse limitaciones de la potestad de libre organización de los servicios públicos locales ${ }^{40}$.

Finalmente, no pueden lógicamente obviarse las reglas establecidas en la Ley de Contratos de las Administraciones Públicas, concernientes tanto al objeto del contrato (artículos $156.4,159$ ) como a las limitaciones que se imponen a la gestión del servicio (161 y 162 de la Ley de contratos y 128.1 y 150.1 del RSCL: igualdad de trato, no discriminación, continuidad).

En general, el Derecho español denota una preocupación especial por evitar la utilización inadecuada o incorrecta de la concesión cuando deba emplearse una forma de gestión directa. Pero no puede tampoco pasarse por alto el problema inverso, es decir, el de la elección de una forma directa de gestión, con el fin de eludir los principios de concurrencia y publicidad previstos por la norma administrativa para la concesión. El fraude de ley es patente cuando, tras decidirse la Administración por la gestión directa, aquélla arrienda directamente el servicio a un particular para que sea éste en definitiva quien lo gestione («rodeo - éste - indirecto a la figura de la concesión administrativa» que detecta la resolución del Tribunal de Defensa de la Competencia, de 21 de septiembre de 1993). Concretamente, la aplicación del Derecho de la competencia gana importancia en este contexto, una vez se ha eludido el Derecho administrativo;

38 Véase J. M. DE la CuÉtara Martinez, La actividad..., págs. 85 y 119; F. Lliset Borreu, «Las sociedades..." y La actividad.... págs. 37, 84 y 161; J. F. MESTRE DELGADO, «La forma de...», pág. 1.227; J. SÁNCHEZ ISAC, Teoria..., págs. 79 y ss.; en la jurisprudencia, en este contexto puede valorarse la STS de 5 de marzo de 1993, Sala 3.", Ar. 1555, en relación con el servicio de recaudación.

39 J. M. Endemaño Aróstegui, «El contrato...», pág. 56; L. F. Prieto González, Las empresas..., págs. 108 y ss.; F. SOSA WAGNER, La gestión..., págs. 92, 177 y 191.

40 Así, la Ley $11 / 1991$, de 8 de abril, de organización y control de las emisoras municipales de radiodifusión sonora, en su artículo 3 prevé necesariamente el sistema de gestión directa. Asimismo, la Ley de 22 de diciembre de 1995 (que regula las telecomunicaciones por cable) requiere concretamente una sociedad anónima. Igualmente, el artículo 69 de la Ley de ordenación de los transportes terrestres - de 30 de julio de 1987- no permite la posibilidad de su prestación en régimen de concurrencia, pues la Ley establece el régimen de exclusiva con carácter general. 
LEVANTAMIENTO DEL VELO Y DERECHO ADMINISTRATIVO...

y por eso, la inaplicación del Derecho de la competencia, que puede producirse en estos casos (tal como infra se estudia), puede representarse como el último eslabón de una proceso de huida completa del ordenamiento jurídico.

\section{La libertad de elección entre formas públicas y privadas de gestión de los servicios públicos locales}

La elección a favor del régimen jurídico privado, respecto de la forma de gestión del servicio público local, se desprende con toda claridad en el Derecho español cuando éste admite que la Administración local pueda optar por la creación de sociedades de capital íntegra o parcialmente público ${ }^{41}$.

La jurisprudencia del Tribunal Supremo es también clara en este punto, como también lo es a la hora de limitar esta opción: las personificaciones de Derecho privado se admiten como «alternativa organizadora», sin que «ello pueda servir para eludir el cumplimiento de sus obligaciones y derechos que consagra el ordenamiento jurídico» ${ }^{42}$. Se reconoce, así, «la utilización por la Administración de técnicas ofrecidas por el Derecho privado, como un medio práctico de ampliar su acción social y económica» ${ }^{43}$, si bien esto «no comporta sin más la exoneración de los principios institucionales de la contratación administrativa, como pueden ser los de publicidad y concurrencia» ${ }^{44}$.

No deja de sorprender que las críticas contra el fenómeno de la huida del Derecho administrativo se hayan volcado sobre la Administración estatal, pasando desapercibida la Administración local, especialmente cuando uno constata que la crítica «en el ámbito estatal» se proyecta sobre todo sobre entidades cuya función es la gestión de un servicio público, considerándose que las entidades que llevan a cabo este tipo de funciones no pueden hacerse regir por el Derecho privado ${ }^{45}$.

\footnotetext{
41 Tradicionalmente en régimen de gestión directa se encuadraban las sociedades de capital integramente público. La Ley de Contratos propugna la conversión de las sociedades mixtas de capital mayoritariamente público en formas de gestión directa, excluyendo el ámbito de aplicación de los contratos de gestión de los servicios públicos de las sociedades de capital mayoritariamente público. De este modo resultaría el siguiente esquema:

1. Sociedad mediante capital íntegra o mayoritariamente público, como formas de gestión directa.

2. Sociedad mixta de capital parcial pero minoritariamente público, como forma de gestión indirecta.

42 STS de 22 de septiembre de 1995, Sala 3.", Ar. 7495; STS de 4 de junio de 1992, Sala 3.. Ar. 4928; STS de 22 de julio de 1986, Sala 3.2, Ar. 5549.

43 STC 14/86, de 31 de enero, STS de 26 de enero de 1995, Sala 3.: Ar. 1502.

44 STC de 11 de mayo de 1983; STC 52/1985, de 24 de febrero.

45

Sobre la huida del Derecho administrativo los trabajos clásicos de M. F. Cl.AVERo ARÉVALo, «Con-
} 


\section{SEGUNDA PARTE: EL PROBLEMA JURÍDICO: LOS POSIBLES FRAUDES DE LEY Y ABUSOS DEL DERECHO}

\section{PLANTEAMIENTO}

El problema jurídico que se plantea es el de los posibles abusos de Derecho y fraudes de ley a los que puede conducir el ejercicio de las potestades mencionadas anteriormente. Concretamente, la libre iniciativa económica, la libertad de organización de los servicios y, por último, la libertad de elección del régimen jurídico, conducen a dibujar un cuadro como el siguiente:

En primer lugar, la potestad de libre organización del servicio puede llevar a eludir el régimen de garantías de la gestión indirecta (esencialmente, los principios de concurrencia y publicidad previstos para la contratación), si se opta por las formas de gestión directa (concretamente una sociedad de capital íntegramente público) «en vez de» una forma de gestión indirecta.

El problema se agrava tras la Ley de Contratos (13/1995, de 18 de mayo), pues esta ley propugna la conversión de las sociedades mixtas de capital mayoritariamente público (tradicionalmente formas de gestión indirecta) ${ }^{46}$ en formas de gestión directa, ya que su artículo 155.2 excluye a este tipo de sociedades (junto al caso justificado de las sociedades de capital exclusiva o íntegramente público) de la aplicación de la regulación de los contratos de servicios públicos ${ }^{47}$. Interesa por el momento retener que la citada ley plantea la posibilidad de eludir los principios propios de la contratación (de las formas de gestión indirecta), al excluir del ámbito de aplicación de la regulación de los contratos de gestión de servicios públicos el caso de las sociedades de capital no sólo íntegramente público sino también mayoritariamente público.

secuencias...», págs. 544 y ss.; F. FleINER, Derecho administrativo..., pág. 263.

Más modernamente, véase M. BACIGALUPO SAGGESE, «Reducción...», págs. 293 y ss.; J. BERMEjo VeRA (Y OTROS), Derecho administrativo..., pág. 62; I. BORRAJo INIESTA, «El intento...», pág. 233; F. GARRIDO FALLA, «Un tema de seguridad juridica...», pág. 391; J. M. Gimeno FELıU, «Una valoración...», págs. 156 y ss.; F. González Navarro, Televisión pública..., pág. 70; F. González Navarro y J. GonzÁlez PÉrez, Régimen jurídico..., págs. 127 a 129; J. C. LAGUNA de PAZ, “La renuncia...», págs. 201 y ss.; S. MARTIN-RetortILlo BAQUER, «Las empresas públicas...", in toto; E. Montoya MARTín, Las empresas..., pág. 86; R. PARAda VÁzquez, Derecho administrativo..., pág. 231; J. M. SAlA ARQUER, «Huida al Derecho privado...», págs. 399 y ss.; S. DEL SAZ CORDERO, «La huida...», págs. 57 y ss.

46 Según el artículo 85.3 de la LBRL, la sociedad mercantil, a la que se refiere la gestión directa ha de ser de «capital social que pertenezca íntegramente a la Entidad social». Iguạlmente, el artículo 89.2 se refiere a la «sociedad privada municipal» como forma de gestión directa en el sentido de que «la Corporación interesada será propietaria exclusiva del capital de la empresa (...)». Véanse también los artículos 62 y 66.4 de la derogada Ley de Contratos del Estado y los artículos 103.c y 104.l del TR.

47 Título II del Libro II. 
LEVANTAMIENTO DEL VELO Y DERECHO ADMNISTRATIVO ...

Por su parte, la «libertad de elección» (que rige en el Derecho administrativo español) entre formas de gestión de Derecho público (un organismo autónomo) y de Derecho privado (una sociedad mercantil) concede la posibilidad de acudir a las formas mercantiles que se rigen en sus relaciones jurídicas por el Derecho privado, eludiendo las garantías del Derecho administrativo (de personal, contratación, bienes y responsabilidad) ${ }^{48}$.

La última pincelada viene de manos del Derecho de la competencia, pues según éste el Tribunal de Defensa de la Competencia no puede conocer del caso si la empresa gestora del servicio público se limita a cumplir lo establecido en un «cuadro normativo o marco jurídico de referencia» para la gestión del servicio. Seguidamente, se profundiza en este criterio y en los referidos problemas.

\section{LAS RESPUESTAS JURÍDICAS QUE SE PLANTEAN (I): EL DERECHO DE LA COMPETENCIA Y SUS LIMITACIONES}

Considerando las facilidades que concede el ordenamiento administrativo para eludir el sistema de garantías jurídicas es importante el Derecho de la competencia, al poder entonces representar éste la única medida de Derecho con la que se enfrenta la actuación en el mercado por parte de los gestores de los servicios públicos locales.

Sin embargo, no puede esperarse del Derecho de la competencia una respuesta de todos y cada uno de los problemas que han sido mencionados. El porqué se deduce de una regla que limita el control del Tribunal de Defensa de la Competencia, según la cual este Tribunal puede sólo conocer del asunto «cuando no existan normas específicas que regulen el comportamiento del monopolista o cuando éste actúe al margen de las mismas, puesto que entonces no existen obstáculos normativos ni de otro tipo que impidan la actuación del Tribunal frente a dichos comportamientos» ${ }^{49}$. El Tribunal conoce de toda práctica contraria a la Ley de Defensa de la Competencia, pero no sobre la regulación del mercado, ya que el control del Tribunal se centra en los efectos que puedan derivarse como contrarios a la competencia. Si esto ocurre, no puede declararse contraria al Derecho de la competencia una práctica (por ejemplo, una fijación de tarifas) a pesar de poder representar un «abuso de posición dominante» (Resoluciones de 30 de octubre de $1993^{50}$; de 24 de enero de

\footnotetext{
48 Sobre esto último, en este contexto, L. MARTín ReBollo, «Medio ambiente...», pág. 644.

49 En este contexto, Resolución de 30 de diciembre de 1993.

s0 Se argumenta, así, que «resulta trascendente determinar si la actividad que se desarrolla en régimen de monopolio se encuentra o no sujeta a regulación, y, en caso afirmativo, si el comportamiento mo-
} 
$1995^{51} ; 30$ de diciembre de $1993{ }^{52} ; 31$ de mayo de $1995^{53}$; de 30 de octubre de 1993, ésta especialmente gráfica en este contexto porque ejemplifica sobre los fraudes de ley administrativa y sobre la discusión que plantea este tipo de cuestiones en el seno del propio Tribunal de Defensa de la Competencia).

Además, el citado Tribunal se muestra especialmente atento a que bajo la apariencia de una práctica contraria a la competencia se esconda la pretensión de control sobre una norma o acto administrativo, función ésta que queda al margen de su jurisdicción (Resoluciones de 18 de octubre de 1993, 25 de julio de 1990, 20 de enero de 1983, 25 de enero de 1985).

De todas estas Resoluciones se desprende cierta insatisfacción en tanto en cuanto dejan a salvo que los poderes públicos puedan vulnerar el Derecho de la competencia; lo único que puede hacer dicho Tribunal en estos casos es remitir al Gobierno una proposición para que éste cambie el marco normativo y elimine las restricciones a la competencia (Resolución de 24 de enero de 1995).

Por otra parte, el Tribunal Supremo limita las facultades del Tribunal de Defensa de la Competencia en orden a la estimación de pretensiones de tipo indemnizatorio: frente a la pretensión de los recurrentes (a favor de que se declarara una práctica prohibida por el TDC y de que éste fijara las indemnizaciones procedentes a favor de la empresa recurrente en contra de otra empresa) la sentencia de 20 de mayo de 1996 (Ar. 4434) afirma que tal pretensión debe ejercitarse ante la jurisdicción civil (de acuerdo con el artículo 6 de la LDC), sin que tampoco pueda considerarse «cuestión prejudicial» ya que es una «cuestión principal».

Todo parece llamar a las puertas de la jurisdicción contencioso-administrativa para que sea ésta quien otorgue respuesta a estos problemas de fraude de ley administrativa y abuso de Derecho por parte de la Administración o de sus

nopolista se ha ajustado estrictamente a las normas establecidas o ha actuado al margen de las mismas». Esto ocurría, a juicio del Tribunal, en el presente caso, por lo que ordenó el archivo del expediente.

sl Según esta Resolución no existe abuso de posición dominante porque la empresa ejerce su actividad dentro de los límites normativos determinados por la ley o por la Administración (véase en Actualidad administrativa, n. ${ }^{\circ} 34,1995$, pág. 1.893).

52 Dice esta Resolución: «cuando por una ley (...) o por una norma reglamentaria que la desarrolla se ha establecido un marco en el que necesariamente ha de moverse el monopolista, el control de la actividad que éste desarrolla al amparo de dichas normas quedará bajo la tutela del regulador y se sustraerá por tanto al conocimiento del Tribunal de Defensa de la Competencia. Asimismo, la infracción de dichas normas deberá ser sancionada por la Administración reguladora o por la jurisdicción contenciosoadministrativa».

53 Según ésta, la aplicación del Derecho de competencia se desarrolla sólo «en áreas no especialmente reguladas o más allá de lo establecido en la regulación correspondiente». 
empresas, tal como estudiamos seguidamente. Bien es cierto que no ha faltado algún pronunciamiento, de gran interés, que ha justificado una extensión del control del Tribunal de Defensa de la Competencia con el fin de que esta instancia pueda declarar contrarias al Derecho de la competencia las prácticas administrativas anticoncurrenciales que se asienten en un fraude de ley administrativa. El ejemplo más importante o significativo es la decisión de 21 de septiembre de $1993^{54}$, que consideró que la Administración no podia ampararse en el hecho de que la sociedad mercantil estuviera cumpliendo un cuadro normativo por ella establecido, con el fin de quedar exenta del control del Tribunal de Defensa de la Competencia. De esta forma, declaró la existencia de un abuso de posición dominante, concretamente la fijación de unos precios por la sociedad gestora del servicio público funerario local, tras entender que quien realizaba la actividad económica era el propio Ayuntamiento, despojándose de sus potestades públicas y entrando en el tráfico mercantil mediante formas estrictamente privadas. En el fondo, la aplicación del «abuso de Derecho» prevaleció sobre los criterios y límites mismos del Derecho de la competencia, sin que la existencia de un marco normativo de referencia pudiese impedir la sujeción a las reglas del Derecho de la competencia por parte de la entidad que gestionaba el servicio ${ }^{55}$.

En esta línea, de profundizar en el Derecho de la competencia, para dar una solución a los problemas de fraude de ley, puede proponerse lege ferenda la extensión de los criterios elaborados por el Tribunal de Justicia de las CC.EE., según los cuales la legislación de los Estados miembros no puede servir de obstáculo para dilucidar judicialmente si la práctica en cuestión es contraria al Derecho de la competencia ${ }^{56}$.

En resumen, el Tribunal de Defensa de la Competencia aporta el conocimiento de un problema de envergadura, cuyo "grueso» no puede cargarse al menos exclusivamente sobre las espaldas de este Tribunal administrativo, ya que, en definitiva, las cuestiones que se suscitan en torno a los servicios públicos son materia de la jurisdicción contencioso-administrativa (artículo 36 del RSCL).

54 Decisión del TDC de 21 de septiembre de 1993 (Ponente Sr. Soriano García). Puede encontrarse publicada en la revista Actualidad administrativa, n. ${ }^{\circ} 35 / 26,1994$, págs. 1.996 y ss.

55 En este mismo sentido, el voto particular de Soriano García a la Resolución de 20 de noviembre de 1994. El fraude se basa en que «el propio ente regulado es el que a través de la captura impone las reglas del monopolio que el mismo disfruta». Véase también la reciente Resolución de 31 de mayo de 1995.

56 No obstante, sólo en el ámbito del Derecho comunitario existe el principio de prevalencia de la legislación comunitaria ( $y$ por tanto también del Derecho comunitario de la competencia) respecto de la legislación de los Estados miembros. Se echa en falta también una mayor atención del artículo 90.2 del Tratado; sobre esto último véase la Resolución de fecha 31 de mayo de 1995 (Actualidad administrati$v a, 1995$, n. $^{\circ} 45$, pág. 2.611), con una mención a los casos Corbeau y Almelo. 


\section{LA TEORÍA DEL LEVANTAMIENTO DEL VELO COMO PARTE DEL DERECHO ADMINISTRATIVO PRIVADO}

\section{A. La doctrina del levantamiento del velo en el Derecho civil español}

La teoría del levantamiento del velo ha arraigado de forma un tanto espectacular en el Derecho privado español. El desarrollo de esta teoría en Europa ha tenido lugar especialmente en Alemania (si bien su inspiración es norteamericana, a través de la doctrina del disregard of the legal entity) ${ }^{57}$. En España la divulgación de esta teoría se produjo a raíz de la traducción de la obra del autor alemán R. Serick (por J. Puig Brutau) ${ }^{58}$. En la actualidad, sin perjuicio de otros preceptos a los que nos referimos infra, deben mencionarse los artículos 133 y siguientes de la Ley de Sociedades Anónimas y el artículo 69 de la Ley de Sociedades Limitadas.

La aplicación de esta doctrina es, por esencia, excepcional, o, como dice la jurisprudencia, «prudencial» ${ }^{59}$, ya que se reserva a la corrección los «abusos de la personificación jurídica» ${ }^{60}$. El principio general no es sino la validez o respeto hacia las personificaciones (las cuales conllevan una actuación independiente respecto de otra persona) ${ }^{61}$ y la excepción es el «fraude de ley» o «abuso de Derecho» mediante la creación de personas juridicas independientes ${ }^{62}$.

57 El propio origen del «concepto de persona jurídica» se vincula generalmente a la Pandectística alemana. Véase C. BOLDÓ RODA, Levantamiento..., págs. 23 y 64.

58 Esta traducción de J. Puig Brutau se enmarca dentro de los trabajos realizados por el Instituto del Derecho comparado, creado hace décadas en Barcelona, ubicado después en Madrid en el seno del Consejo Superior de Investigaciones Científicas, y posteriormente clausurado.

59 STS de 6 de junio de 1992, Sala 1.", Ar. 5165; STS de 24 de septiembre de 1987, Sala 1.2

60 Sobre éstos, F. DE CASTro y Bravo, La persona juridica..., pág. 21; A. Polo en el Prólogo a la obra de R. Serick (traducida por J. Puig Brutau), Apariencia...

61 Un gráfico ejemplo de esto es la Sentencia de la Audiencia Territorial de La Coruña de 21 de abril de 1988 (Sala 2."), Revista General del Derecho, abril, n. 535 (1989), pág. 2.536, que exime de toda responsabilidad al Ayuntamiento por corresponder aquélla a la sociedad, ya que «una de las finalidades que llevó al legislador a permitir que las Corporaciones locales pudieran gestionar los servicios públicos de su incumbencia, recurriendo a la creación de una sociedad mercantil (...) fue la de reducir la responsabilidad de la Corporación por la actuación de ese servicio, al capital que dicha corporación afectó a ese fin bajo la forma de sociedad capitalista».

62 Sobre la doctrina del levantamiento del velo en el Derecho común, junto a las sentencias que se citarán infra, pueden verse las siguientes: STS de 16 de febrero de 1994 (RJ 1994, 1618); STS de 30 de julio de 1994 (RJ 1994, 6308); STS de 10 de noviembre de 1994 (RJ 1994, 8464); STS de 24 de febrero de 1995 (RJ 1995, 1111); STS de 7 de junio de 1995 (RJ 1995, 4629); STS de 12 de junio de 1995 (RJ 1995, 4739); STS de 20 de julio de 1995 (RJ 1995, 5715); STS de 21 de julio de 1995 (RJ 1995, 5729); STS de 11 de noviembre de 1995 (RJ 1995, 8118). En la doctrina, véase R. DE ÁNGEL YÁGÜEZ, La doctrina del levantamiento del velo..., in toto; C. R. FERNÁNDEZ RODRÍGUEZ, "Comentario a Serick...», págs. 975 y ss.; J. M. EMbid Irujo, «En tomo al "levantamiento del velo...», págs. 3 y ss.; P. M. Rodríguez Rosales, «La 
LEVANTAMIENTO DEL VELO Y DERECHO ADMINISTRATIVO ..

Pero cuando esto último ocurre, el levantamiento del velo presenta la virtualidad de «evitar que al socaire de esa ficción o forma legal se puedan perjudicar intereses privados o públicos como camino del fraude (artículo $6.4 \mathrm{del} \mathrm{CC}$ ), admitiéndose que los jueces puedan penetrar (levantar el velo jurídico) en el interior de esas personas cuando sea necesario para evitar el abuso de esta independencia (artículo 7.2 del CC) en daño ajeno o de los derechos de los demás (artículo 10 de la $\mathrm{CE}$ ), o, en general, que pueda ser utilizada como camino del fraude (artículo 6.4 del Código Civil)» ${ }^{63}$ o como camino de «un eventual enriquecimiento injusto» ${ }^{64}$.

De lo que se trata es de coartar las ventajas injustificadas, que permite la creación de una persona interpuesta (relativas al régimen de responsabilidad o fiscal) ${ }^{65}$, porque «no puede crearse una situación fraudulenta de insolvencia» ${ }^{66}$.

La doctrina del levantamiento del velo se enfrenta, pues, con el supuesto de las sociedades que «sirven de pantalla»; siguiendo la jurisprudencia civil, el fraude se constata cuando al «levantar el velo de su apariencia real se descubre su inconsistencia como personas jurídicas, meros instrumentos o testaferros de otra personalidad, que es la que se debe tener por existente» ${ }^{67}$.

El mérito de esta doctrina está en su espíritu garantista en favor de los terceros perjudicados, permitiendo responsabilizar a las personas que se amparan bajo la cobertura de la sociedad (cuando se identifique un abuso jurídico o un fraude de Ley) con el fin de que aquéllas asuman las consecuencias jurídicas derivadas de su actuación. Entonces, estos fines prevalecen frente al dogma de fe de la personificación y, en este sentido, la jurisprudencia viene a reconocer la primacía del valor de la «justicia material» sobre el valor «formalista de la personificación jurídica» ${ }^{68}$. O, quizá, a efectos de conciliar ambos pueda decirse que «no es de reconocer la independencia de dos distintas personalidades cuan-

doctrina del levantamiento de velo...», págs. 393 y ss.; M. A. Rulz Ferreiro, «El levantamiento del velo...", págs. 1.044 y ss.

63 STS de 24 de septiembre de 1987, Sala 1.; STS de 8 de febrero de 1996, Sala 1.", Ar. 862; en esta línea, también la STS de 12 de febrero de 1993, Sala 1.", Ar. 763; Sentencia de 7 de febrero de 1996 de la Audiencia Provincial de Teruel Ar. - AP 300-.

64

STS de 2 de diciembre de 1988, Sala 1. Ar. 9287.

C. Boldó RodA, Levantamiento..., págs. 24 y 36.

66 STS de 13 de mayo de 1988, Sala 1., Ar. 4306, pág. 4.213: «la personalidad jurídica que la Ley reconoce a las sociedades no puede ser utilizada para fines como el que se contempla, consistente en que una vez vendido el Hotel ... se carece de cualquier tipo de bienes raíces, pudiendo calificarse su situación actual como de insolvencia».

STS de 24 de diciembre de 1988, Sala 1.", Ar. 9816.

68

J. M. Embid Irujo, Prólogo al libro de C. Boldó Roda, Levantamiento..., pág. 18. 
do al levantar el velo de una apariencia legal se descubre la inconsistencia de la personalidad jurídica de una determinada sociedad» ${ }^{69}$.

Por todo ello, esta teoría del levantamiento del velo pretende revelar la «verdad material subyacente» ${ }^{70}$ frente a la «apariencia», pues puede en efecto que «sólo en apariencia la entidad mercantil funcione con independencia de su persona» ${ }^{71}$. En este sentido, los Tribunales reconocen no haber "vacilado en apartar el artificio de la Sociedad anónima para decidir los casos según la realidad» ... pues «prevalece un principio ético» con apoyo en el principio de buena fe (artículo 7.1 del CC) ${ }^{72}$. En suma, como dice otra sentencia, ha de penetrarse en el sustratum personal de las entidades o sociedades a las que la ley confiere personalidad jurídica propia ${ }^{73}$.

El levantamiento del velo es una doctrina de vocación esencialmente jurisprudencial, pues, ante todo, aporta un criterio de equidad ${ }^{74}$. Se ha dicho, así, que «gracias al levantamiento del velo pueden nuestros Tribunales disponer de un expediente adecuado para salvar los resultados injustos que se producirían, a su juicio, aplicando en todo su rigor el régimen jurídico propio de las sociedades de capital», llamando la atención, de otra parte, que «el recurso generalizado al levantamiento del velo en nuestra jurisprudencia se haya hecho sin base legal explícita, fuera de ciertas cláusulas generales recogidas en la Constitución y el Código Civil». Y, entonces, que si bien «no cabe discutir, en modo alguno, la licitud de esa fundamentación, sí sorprende la frecuencia de tales pronunciamientos, que ponen de manifiesto una cierta ineficiencia del Derecho vigente más preocupado por la estabilidad formal de la persona jurídica societaria que por la tutela de otros intereses o la represión de conductas abusivas ${ }^{75}$.

\section{B. La teoría del levantamiento del velo como parte del Derecho administrativo privado}

En el Derecho alemán, en el cual —como decíamos- se ha desarrollado especialmente la teoría del levantamiento del velo, ésta se ha elaborado no sólo

69 STS de 16 de marzo de 1992, Sala 1.:, Ar. 2189. La cursiva es nuestra.

STS de 8 de febrero de 1996, Sala 1., Ar. 862.

STS de 9 de julio de 1987, Sala 1.^, Ar. 5209.

STS de 24 de septiembre de 1987, Sala 1.".

STS de 6 de junio de 1992, Sala 1., Ar. 5165. 
LEVANTAMIENTO DEL VELO Y DERECHO ADMINISTRATIVO ...

en el Derecho civil sino también en el Derecho administrativo (Formenmißbrauch, Mißachtung der Rechtsform). En realidad, aquélla es una parte del Derecho administrativo privado (Verwaltungsprivatrecht). Éste consiste en la afirmación de la aplicación de la norma administrativa que la Administración pretende inaplicar o eludir, acudiendo al Derecho privado o a un ente interpuesto. Invocando el «Derecho administrativo privado», la jurisprudencia mantiene que «la Administración Local no puede aprovechar su libertad de elección de la forma jurídico-privada para atribuirse ventajas en cuanto al régimen jurídico» ${ }^{76}$ porque «ni en el ámbito del Derecho público ni en el del Derecho privado se pueden ejercitar los derechos o emplear las formas jurídicas, con el fin de otorgarse ventajas o de eludir la ley, ya que ello sería un abuso de derecho" ${ }^{77}$. En este sentido, el Tribunal Supremo alemán («Sala de lo contencioso-administrativo») ${ }^{78}$, entiende que «la Administración no podrá elegir libremente la forma jurídica para la gestión del servicio porque ésta ha de ser la más adecuada con el fin que se propone llevar a cabo».

Lo que el Derecho administrativo privado pretende es que la Administración, «mediante el juego de la elección de las formas jurídicas y de la creación de personas jurídicas independientes, no se libre de las responsabilidades que le incumben" ${ }^{79}$. Lo contrario puede venir asociado a un fraude de ley administrativa y esto es, precisamente, lo que debe corregirse. Esta última variante $o$ manifestación, del Derecho administrativo privado, encaja dentro de lo que en el Derecho español se entiende como teoría del levantamiento del velo ${ }^{80}$. En este sentido, el levantamiento del velo permite que el juez administrativo ordene la aplicación de la norma de Derecho administrativo que pretende eludirse considerando que la entidad instrumental empleada es una simple prolongación de

76 Sentencia de 28 de enero de 1954 del Tribunal Superior de Justicia de Nordhein-Westfalen ( $«$ Sala de lo contencioso-administrativo", nwOVGE 8, pág. 217). Esta doctrina se recogí antes en la Ley imperial de tributos de 13 de diciembre de 1919, así como en la Ley de impuestos de 16 de octubre de 1934.

77 En la misma línea («impidiendo el abuso de derecho»), la Sentencia del Tribunal Supremo alemán de fecha 25 de octubre de 1957, recogida en DÖV 1958, pág. 388.

78 Sentencia de 11 de febrero de 1993: BVerwG, en NJW 1993, págs. 2.695 y ss. (pág. 2.697); igualmente, véase $N J W 1985$, pág. 1.982 y $D V B l 1985$, pág. 794.

79 Sentencia del Tribunal Supremo alemán («Sala de lo contencioso-administrativo»), de 7 de noviembre de 1957, en relación con el tema del abuso de derecho en la aplicación del Derecho privado (BVerwG en NJW 1958, pág. 394). Véanse igualmente, las siguientes sentencias: prOVGE, 87, 270; prOVPE 7, 146; VGH Freiburg, BwVBl 1956, 77.

80 En gran medida los problemas de fraude de ley podrían resolverse si la legislación determinara la forma de gestión que debe emplearse en el caso concreto, como parece ocurrir en el Derecho comparado. Así, las Leyes de aguas de Schleswig-Holstein (artículo 35.4.1) y de Baden-Würtemberg (artículo 45.3) imponen las formas de Derecho público; o se condiciona la posibilidad de la forma privada a la presencia de ciertos presupuestos (artículo 65 de la Ley General de Presupuestos de 19 de agosto de 1969). Puede verse, asimismo, el artículo 44 III de la Ley local de Sajonia. 
REALA 274-275 (MAYO-DICIEMBRE. 1997)

la Administración Local de la que ésta se sirve para el cumplimiento de sus propios fines, porque «los entes institucionales no tienen fines propios, sino que actúan directamente los fines de sus fundados, el Ayuntamiento» tal como declara el Tribunal Supremo español en su sentencia de 7 de febrero de 1994 (Ar. 1008).

\section{LEVANTAMIENTO DEL VELO EN EL DERECHO ADMINISTRATIVO ESPAÑOL}

Una vez hemos visto su sentido y virtualidades en el ámbito general, del Derecho civil, corresponde a continuación observar cómo se manifiesta esta teoría en relación con la Administración o sus empresas, cuándo procede, y qué consecuencias tiene.

En este sentido, la sentencia del Tribunal Supremo de 28 de mayo de $1984^{81}$ puede considerarse un hito jurisprudencial en el Derecho español, porque es la que introduce ${ }^{82}$ de forma decidida la teoría del levantamiento del velo, precisamente con ocasión de un pleito administrativo ${ }^{83}$. En este asunto, un Ayuntamiento se amparaba en la existencia de una sociedad mercantil con el fin de esquivar una acción de responsabilidad civil considerando prescrita la acción, ya que la reclamación administrativa (previa al ejercicio de las acciones judiciales) no podía interrumpir el plazo de prescripción en tanto que la sociedad gestora del servicio (causante de los daños) era independiente del Ayuntamiento, con personalidad jurídica propia distinta de aquél y no existía responsabilidad solidaria de ambos.

El Tribunal aplicó las nociones de buena fe, de abuso del Derecho y de fraude de Ley para mantener que el Ayuntamiento no podía escudarse en la existencia de una sociedad intermediaria de Derecho civil con el fin de eludir el artículo 1973 del CC, de obligado cumplimiento para la Administración.

En suma, este pronunciamiento partía del respeto hacia la «personificación», corrigiendo no obstante los abusos que se generaban ${ }^{84}$.

\footnotetext{
81 Sala 1.', Ar. 2800.

82 C. BoLDo, Levantamiento..., pág. 216 pese a que, como este libro resalta, existe un antecedente en la Sentencia de 8 de enero de 1980, RJ 1984, 2800.

83 Sobre esta sentencia, por todos, J. M. EMBID IRUjo, «Los grupos de sociedades...», pág. 51. Críticamente, P. PANTAleÓN PRIETO, «Comentario...", págs. 1.711 y ss.

84 Puede verse el Considerando Cuarto.
} 
LEVANTAMIENTO DEL, VELO Y DERECHO ADMINISTRATIVO ...

Pero interesa aquí resaltar especialmente la aplicación del levantamiento del velo (y, por tanto, del Derecho administrativo privado), en la jurisprudencia de la jurisdicción contencioso-administrativa. Los casos que a continuación se exponen afectan todos ellos a la Administración Local.

Puede empezarse por una resolución judicial que distinguió entre la existencia de un plano ficticio y otro real, con el fin de descubrir un fraude de ley, exigiendo entonces el cumplimiento de la norma que pretendía ser inaplicada. Así, la sentencia del Tribunal Supremo de 31 de julio de $1992{ }^{85}$ negó que la persona jurídica en cuestión «fuera ajena al municipio» (situación aparente), ya que en realidad «la sociedad privada actuaba dentro de la Administración del Ayuntamiento como órgano diferenciado del mismo pero en cumplimiento de sus fines; órgano de gestión de un servicio municipal con personalidad jurídica diferenciada, pero no ajena a la Corporación Municipal en la que se integra» ${ }^{86}$.

Levantado el velo se descubre, pues, que la personalidad diferenciada en este caso era una simple «circunstancia formal»; el Tribunal pretende con todo ello «que se cumplan las obligaciones referidas al servicio público municipal». Interesante es el Fundamento de la sentencia, según el cual la «sociedad privada actúa en cumplimiento de los fines de la Corporación; actividad de la Corporación que no se halla exenta de las obligaciones asumidas por dicha sociedad privada». En principio, primaría, así pues, el dato de la personificación del sujeto; pero no como dogma sino a sabiendas de que es un criterio que puede contradecirse en cada supuesto.

La relativización de la personificación se ha hecho también con el fin de evitar que a su socaire la Administración Local eluda su comparecencia en el proceso. Así, la sentencia del Tribunal Supremo de 20 de febrero de $1995^{87}$ afirma que «el Ayuntamiento puede ser también demandado pues la personalidad del Patronato es meramente operativa e instrumental». Se basó para ello en que los miembros de su Junta Rectora eran miembros de la Corporación y también en que sus aportaciones provenían de la Corporación local. Lo contrario no se correspondería con «la realidad subyacente en el proceso» en clara alusión a la jurisprudencia del levantamiento del velo.

Igualmente, la sentencia del Tribunal Supremo de 22 de septiembre de $1995^{88}$ negó que la personificación jurídica independiente de un organismo autónomo

\footnotetext{
85 Sala 3.", Ar. 6596.

86 En este sentido, también la STS de 7 de febrero de 1994 (Ar. 1008).

87 Sala 3.", Ar. 6188.

88 Sala 3.: Ar. 7495.
} 
pudiera ser alegada por un Ayuntamiento como pretexto para no ser demandado procesalmente. El Tribunal partía de la validez de la forma de personificación jurídica independiente, pero este hecho no podía llevar a eludir las obligaciones que impone el ordenamiento jurídico. La personificación (y con ello la opción a favor del Derecho privado) es una simple opción de los poderes públicos en aras a facilitar la gestión de los servicios públicos. Por eso la sentencia, citada, de 22 de septiembre de 1995 dice que:

«Estos datos comportan que la personalidad y capacidad de Fundación Pública Teatro Municipal Miguel de Cervantes son sólo operativas o instrumentales, suponiendo nada más que la autonomía funcional a que se refiere el artículo 1 de los estatutos, realizada a través de una Gerencia de libre designación. Y ello no es suficiente para relevar al Ayuntamiento de responsabilidad, aunque sólo sea subsidiaria, en las obligaciones contraídas por el teatro para cumplimiento de fines municipales». $1992^{89}$ :

Porque, tal como prevé la sentencia del Tribunal Supremo de 4 de junio de

«(...) La personificación como instrumento de la potestad organizatoria de la Administración no puede utilizarse por los entes públicos para eludir el cumplimiento de sus obligaciones y derechos que consagra el ordenamiento jurídico...» (en el presente caso el sistema de responsabilidad administrativa).

En definitiva, «la personificación es sólo una alternativa organizadora». Lo determinante para deducir el régimen jurídico que ha de corresponder a una entidad es la función que ésta esté realizando, por encima de su forma jurídica. Porque «no hay en efecto en el ordenamiento español una regulación de la persona jurídica en virtud de la cual baste con invocar este sintagma para que sepamos qué régimen jurídico hay que aplicar. Éste se articula en cada caso» (STS de 22 de julio de 1986) ${ }^{90}$.

Estos criterios, como puede verse, están en la base de las teorías del Derecho administrativo privado y del levantamiento del velo, cuyo fin no está sino en evitar que la Administración Pública eluda las normas del Derecho administrativo mediante la utilización instrumental del Derecho privado: aunque se escoja una forma de Derecho privado, la identificación de la función pública de la entidad conlleva la imposibilidad de burlar o inaplicar el Derecho administrativo. Es justamente ejemplar de esto la sentencia del Tribunal Supremo de

89 Sala 3.:, Ar. 4928.

90 Sala 4.: Ar. 5549. 
LEVANTAMIENTO DEL VELO Y DERECHO ADMINISTRATIVO ...

22 de septiembre de $1994^{91}$. Se trataba de dilucidar si era aplicable una regulación de Derecho administrativo (artículo 107.1 in fine del Texto Refundido de 18 de abril de 1986) respecto de una entidad de Derecho privado ${ }^{92}$; de forma interesante, la sentencia apoyó la aplicación del Derecho administrativo considerando el fin o naturaleza de la actividad realizada:

«Atendiendo a la naturaleza de la actividad desarrollada, suele distinguirse entre servicio público y actividad privada. La actividad de servicio público, subjetivamente, es competencia de ente público y está sometida a un régimen jurídico determinado, exigido porque todo servicio público comporta la satisfacción de un interés de la colectividad, interés que, la mayoría de las veces, da lugar a un servicio público esencial, como es el caso del suministro de agua a los ciudadanos (...) El elemento subjetivo que presta el servicio cede como elemento relevante ante el elemento de la actividad desarrollada para satisfacer un interés público, bajo un régimen jurídico propio del Derecho administrativo (...). Dado el interés público al que servía la actividad (suministro de agua a una urbanización) es aplicable el artículo 107.1 del Texto Refundido.»

Igualmente, en la sentencia del Tribunal Supremo de 18 de mayo de $1995^{93}$ se sienta que, a pesar de que la empresa sea una entidad privada, como su actividad realizada es pública («un suministro de agua a poblaciones»), debe aplicarse la norma administrativa ${ }^{94}$ que regula la elevación de tarifas por el suministro, de acuerdo con el procedimiento en ella establecido ${ }^{95}$.

Prima, como puede verse la constatación del tipo de función realizada y de la consideración de ésta como una «prolongación de la actividad del propio Ayuntamiento -en el ente instrumental-». Siendo la actividad pública, no podrán eludirse las obligaciones de Derecho administrativo. Por eso, «el elemento subjetivo que presta el servicio cede como elemento relevante ante el elemento de la actividad desarrollada para satisfacer un interés público, bajo un régimen jurídico propio del Derecho administrativo», dice expresamente la sentencia de 22 de septiembre de $1994^{96}$.

\footnotetext{
91 Sala 3.", Ar. 7137.

92 En este caso, el Ayuntamiento era quien basaba el carácter privado de la entidad para no reconocer la prestación que le concedía el artículo 107 del Texto Refundido — de revisión de tarifas-.

93 Sala 1.:, Ar. 3861.

94 Concretamente la Orden Ministerial de 30 de septiembre de 1977.

95 Puede verse también la STS de 10 de enero de 1992 (Sala 3." -Sala de lo contencioso-administrativo-), en su Fundamento de Derecho Primero 2. 1.'.

96 Véase también la Sentencia del Tribunal Supremo de 31 de julio de 1992, Sala 3.", Ar. 6596.
} 
Todo ello no significa que el levantamiento del velo no deba interpretarse o aplicarse de una forma prudencial; no podría llegarse a un «abuso en la invocación del abuso del Derecho». Los fraudes o huida del Derecho se definen por su carácter de excepción. En este sentido, la jurisprudencia civil exige la «existencia de un propósito defraudatorio», hecho que no ocurre si «la actuación de los administradores se presenta diligente» ${ }^{97}$. En el campo del Derecho administrativo, y por referencia a la Administración Local, interesante es en este contexto la sentencia de 17 de enero de 1995 del Tribunal Supremo ${ }^{98}$ : una empresa pública local (de abastecimiento y saneamiento de aguas) se apoyaba en la doctrina del levantamiento del velo para considerar que el patrimonio afectado por una liquidación tributaria era del propio Ayuntamiento, con lo cual sería inexigible la fianza establecida en el artículo 154.2 de la Ley 39/1988, de 28 de diciembre. El Tribunal tuvo que pronunciarse acerca de si podía entenderse aplicable dicha teoría del levantamiento del velo, a favor de las propias instancias administrativas, que pretendían no tanto eludir como más bien beneficiarse de una regulación jurídico-administrativa. El Tribunal negó en este caso que, de la identidad sustancial de ambas, pudiera derivarse la «extensión al sujeto instrumental de una exención que en principio sólo se predicaba legalmente al ente público territorial».

Puede, así, terminarse este apartado recapitulando sobre los presupuestos y los fines de la teoría del levantamiento del velo, en este contexto. Aquéllos podrían ser entonces, primero, la existencia de un fraude de ley y, segundo, la presencia de un fraude causado mediante la creación de una persona jurídica. A efectos de profundizar en la identificación de una situación de fraude de ley ilustra la STS (Sala 3. ${ }^{a}$ ) de 20 de octubre de $1995^{99}$ por la que un Ayuntamiento pretendía eludir una norma de Derecho público, que era el Texto Refundido del Impuesto sobre Transmisiones Patrimoniales y Actos Jurídicos Documentados, de 30 de diciembre de 1980 (artículo 7.1.b), mediante la consideración de un contrato como arrendamiento en vez de concesión ${ }^{100}$; o la STS de 23 de diciembre de $1988^{101}$ que se enfrenta con una calificación fraudulenta de un

97 STS de 5 de febrero de 1996, Sala 1. , Ar. 1341.

98

Sala 3. , Ar. 1652. Igualmente véase la STS de 24 de octubre de 1995, Sala 3.", Ar. 9945.

99

$1996-2 \S 555$.

100 El contrato tenía como objeto el servicio de recogida domiciliaria de residuos sólidos urbanos y limpieza de vías públicas. La sentencia no aporta una doctrina importante en cuanto al complejo problema de la delimitación entre concesión y arrendamiento, y sigue la famosa STS de 17 de marzo de 1979. Se baso aquélla en el artículo 13.2 del Texto Refundido del Impuesto, según el cual quedan sujetos al mismo «los actos o negocios administrativos, cualquiera que sea su denominación, que se otorguen como consecuencia de facultades de gestión de servicios públicos o de la atribución del uso privativo o del aprovechamiento especial de bienes de dominio o uso público y se origine un desplazamiento patrimonial en favor de los particulares».

101 Puede consultarse en $A A$ n. 26 (1989) $\$ 423$. 
LEVANTAMIENTO DEL VELO Y DERECHO ADMINISTRATIVO...

contrato como privado con el fin de eludir las normas de contratación administrativa, frente a lo que reacciona el Tribunal sentando «la improcedencia de aplicar el Derecho privado cuando existen normas sobre la materia en el Derecho administrativo».

Finalmente, en relación con los fines de la doctrina del levantamiento del velo en el Derecho administrativo, puede destacarse el planteamiento garantista a favor de terceros que puedan resultar perjudicados por el juego de las personificaciones realizado por los poderes públicos, así como el reforzamiento del principio de legalidad administrativa, al prevenir frente a los posibles fraudes de ley administrativa.

\section{El problema de la jurisdicción competente}

Como ha podido advertirse, la doctrina del levantamiento del velo se manifiesta tanto en el orden jurisdiccional civil como en el contencioso-administrativo; desde el punto de vista de las actuaciones administrativas fue la jurisdicción civil la que primero ha aplicado dicha doctrina (Sentencia de 28 de mayo de 1984, cit.).

Tratándose de una materia de organización de los servicios públicos parece lógico que sea la jurisdicción contencioso-administrativa la que conozca de estos asuntos, tal como por cierto establece el artículo 36 del RSCL, que atribuye a la jurisdicción contencioso-administrativa el conocimiento de todas las cuestiones que se sustancien respecto a las resoluciones de las Corporaciones locales sobre constitución, organización, modificación y supresión de los servicios públicos. Por otra parte, estas relaciones jurídicas tienen naturaleza administrativa ya que han de interpretarse a la luz de una legislación administrativa, y ya que participa o interviene la Administración pública.

Consecuentemente, la jurisdicción contencioso-administrativa seguramente no habría afirmado la siguiente doctrina (contenida en la sentencia del Tribunal Supremo de 31 de diciembre de 1993 , Sala $1 .^{a}$ ) ${ }^{102}$ : la «doctrina del levantamiento del velo parte de la existencia de mala fe, actuar fraudulento o abusivo en la personalidad jurídica para evitar responsabilidades» (...); por eso aquélla «no puede trasladarse al Estado y sus organismos autónomos pues en modo alguno pueden achacárseles tales conductas en la organización de sus instituciones». Estas afirmaciones son un tanto ingenuas; en la base del Derecho administrativo se sitúa, más bien, una idea de desconfianza hacia el poder público ${ }^{103}$. El reciente

102 Ar. 9925.

103 Por todos J. Pérez Royo, El Tribunal Constitucional..., in toto. 
proceso de huida generalizada del Derecho administrativo puede servir para corroborar fácilmente la necesidad de desarrollar mecanismos de control frente «al Estado y sus organismos autónomos». En conclusión, el control civil se justificaría sólo en tanto en cuanto no se desarrollara un control por parte de la jurisdicción contencioso-administrativa (artículo 9.2 de la LOPJ).

\section{E. El Derecho administrativo privado y las sociedades de Derecho privado de capital mayoritariamente público (del artículo 155.2 de la Ley de Contratos)}

Como antes apuntaba, el artículo 155.2 de la Ley de Contratos propugna la inaplicación de las reglas contenidas para los contratos de gestión de servicios públicos respecto de las sociedades de Derecho privado cuyo capital sea mayoritariamente público, y en general de los principios de la contratación de la Administración (publicidad y concurrencia), previstos para las formas de gestión indirectas de los servicios públicos. Para corregir esta situación, se han presentado construcciones doctrinales interesantes en este contexto. SALA ARQUER estima como dato decisivo - para establecer si una empresa mixta puede ser considerada como una forma de gestión directa - no el de la participación mayoritaria de la Administración (que se desprendería de una primera lectura del tenor literal del citado artículo 155.2) sino el de si la Administración tiene una «reserva de los puestos de dirección y gerencia de la empresa, quedando el capital privado al margen de la gestión de la misma» ${ }^{104}$. Mediante este último presupuesto se relativiza el criterio de la participación mayoritaria y las cosas no se presentan tan fáciles para la Administración, evidentemente, a efectos de eludir las garantías previstas para la contratación de gestión de servicios públicos ${ }^{105}$. SOSA WAGNER llega a una misma conclusión en el sentido de considerar que la exclusión no podrá referirse más que a la regulación de los contratos de gestión de servicios públicos (esto es, el Título II del Libro II de la Ley de Contratos) debiéndose aplicar los principios - de la adjudicación de contratos administrativos- de publicidad y concurrencia ${ }^{106}$. Ambas posiciones pretenden evitar el fraude de ley que supondría la utilización de estas formas de gestión «indirec-

104 Para un estudio de las posturas doctrinales que han defendido este (conocido) criterio para definir las sociedades mixtas, puede verse L. F. PRIETo GonzÁlez, Las empresas..., págs. 42 y ss. (67, 7I) y 143 y ss. $(154,207)$.

105 J. M. SALA ARQUER, «La empresa mixta...», pág. 233. Cuando se presenta dicho requisito entonces puede decirse que la participación pública mayoritaria tiene «unos efectos análogos a los de la participación exclusiva de la Administración».

106 A. Ballesteros Fernández, «La aplicación...», pág. 2.343; J. M. ENdemaño ArósteguI, «El contrato...», pág. 49; igualmente, F. J. FERnÁNDEZ GonzÁlez, «La Ley...», págs. 873 y ss.; F. SOSA WAGNER, La gestión..., págs. 64, 84 y 190. 
LEVANTAMIENTO DEL VELO Y DERECHO ADMINISTRATIVO ...

ta» con el fin de eludir la regulación general en materia de contratos, porque tampoco pasan por alto que la Ley de Contratos no deja lugar a dudas de su voluntad de extender al máximo las garantías de publicidad y concurrencia (artículo 11.1). Pues bien, baste entonces con decir que el Derecho administrativo privado es una teoría de vocación judicial que tiene como finalidad evitar la inaplicación de una norma administrativa que pretende eludirse, en nuestro caso la Ley de Contratos.

\section{TERCERA PARTE: EL PROBLEMA DE LA SUJECIÓN A DERECHO DE LA ACTIVIDAD AD EXTRA DE LA FORMA DE GESTIÓN DEL SERVICIO PÚBLICO}

\section{EL «PROBLEMA»Y EL DERECHO ADMINISTRATIVO PRIVADO}

Junto al problema anterior se sitúa el del control sobre la actuación ad extra de las entidades gestoras del servicio. Concretamente el «problema» se plantea (por ser una situación criticable y criticada jurídicamente) cuando la actividad del ente se hace regir por el Derecho privado y, más concretamente, cuando la función que aquél desarrolle sea la gestión de un servicio público - no una simple actuación mercantil-. En este contexto puede presentarse el Derecho administrativo privado, doctrina que tiende a evitar que se inaplique el Derecho administrativo cuando la Administración (o sus empresas o entidades interpuestas) cumpla sus funciones propias (o públicas, no puramente mercantiles), a pesar de que se haya definido inicialmente su régimen jurídico conforme al Derecho privado.

Como fácilmente puede comprenderse, los destinatarios directos de esta teoría son los tribunales. Y, en este sentido, la jurisprudencia del Tribunal Supremo se sitúa en consonancia con este planteamiento doctrinal, cuando afirma que el Derecho privado se admite como «alternativa organizadora», sin que «ello pueda servir para eludir el cumplimiento de sus obligaciones y derechos que consagra el ordenamiento jurídico» ${ }^{107}$, reconociéndose «la utilización por la Administración de técnicas ofrecidas por el Derecho privado, como un medio práctico de ampliar su acción social y económica» ${ }^{108}$, si bien esto «no comporta sin más la exoneración de los principios institucionales de la contratación administrativa, como pueden ser los de publicidad y concurrencia» ${ }^{109}$.

107 STS de 22 de septiembre de 1995, Sala 3.", Ar. 7495; STS de 4 de junio de 1992, Sala 3.', Ar. 4928; STS de 22 de julio de 1986, Sala 3.", Ar. 5549.

108 STC 14/86, de 31 de enero, STS de 26 de enero de 1995, Sala 3.: Ar. 1502.

109 STC de 11 de mayo de 1983; STC 52/1985, de 24 de febrero. 
Asimismo, según la jurisprudencia (esta vez, procedente del Derecho alemán) «la empresa pública local puede hacerse regir por el Derecho privado, pero en sus relaciones jurídicas está vinculada por el principio de igualdad, ya que su función es pública, esto es, la gestión de un servicio público»" ${ }^{110}$.

No obstante, a veces el régimen del Derecho administrativo privado encuentra también apoyos claros en la propia legislación, cuestión ésta cuyo estudio se reserva para más adelante (véase infra § IV, «los criterios funcionales»).

\section{LA TEORÍA DE LOS ACTOS SEPARABLES}

La teoría de los actos separables permite un control de la jurisdicción contencioso-administrativa respecto de un acto (administrativo) que puede deducirse de una relación jurídico-privada. La doctrina de los actos separables tiene, por eso, un alcance esencialmente procesal. En el Derecho español se ha incidido en la necesidad de un control del contencioso-administrativo respecto de fases esenciales de negocios jurídico-privados, tanto en un plano doctrinal ${ }^{111}$ como por parte de los tribunales ${ }^{112}$ o del Consejo de Estado ${ }^{113}$. Cuando la extensión del Derecho privado ha dejado de ser un fenómeno inesencial para alcanzar recientemente vastas proporciones ${ }^{114}$ parece razonable sostener el encaje de la teoría procesal de los actos separables dentro de la doctrina general del De-

\footnotetext{
110 Sentencia de 23 de septiembre de 1969, del Tribunal Supremo alemán («Sala de lo civil»); igualmente, sentencia del mismo Tribunal, de 5 de abril de 1984 (también «Sala de lo civil») BGHZ 91, 84 y sentencia del Tribunal Superior de Justicia de Lüneburg (esta vez de la jurisdicción contencioso-administrativa), de 11 de julio de 1989, $N V w Z 1990$, págs. 91 y ss.
}

111 Recientemente, S. MARTIN-RETORTILL BAQUER, ha considerado equivalentes los «actos separables» y el «Verwaltungsprivatrecht» alemán (Derecho administrativo privado): S. MARTíN-RETORTLLO BAQUER, «Reflexiones sobre la huida...», págs. 54 y ss.

Sobre la teoría de los actos separables, junto a E. García dE ENTERría y T. R. FERNÁNDEZ, Curso..., púgs. 51 y 383 y ss., también los trabajos de A. CARRETERo, «La teoría de los actos separables...», págs. 83 y ss.; M. F. Clavero Arévalo, «El estado actual...», pág. 545; J. A. García-Trevijano Fos, «Contratos y actos...», págs. 147 y ss.; del mismo autor, «Reciente evolución...», págs. 227 y ss.; G. FERNÁNDEZ FA. RRERES, La subvención..., págs. 301 y ss.; E. RIVERO YSERN, «¿Actos separables...», pág. 701; del mismo autor, «Derecho público y Derecho privado...», pág. 52.

112 En relación con los actos separables, por ejemplo STS de 27 de diciembre de 1994, Sala 3.:, Actualidad administrativa, n. ${ }^{\circ} 23,1995$; Sentencia del Tribunal Superior de Justicia de Cataluña de 9 de marzo de 1990 (Sala de lo contencioso-administrativo); STS de 25 de abril de 1994, Sala 3.", Actualidad administrativa, n. $47,1994$.

113 Puede citarse el Dictamen del Consejo de Estado sobre el Anteproyecto de la Ley de Contratos del Estado de 3 de diciembre de 1993 y el interesante Dictamen de fecha 5 de noviembre de 1992 , n. ${ }^{\circ}$ 1391/92, Recopilación de Doctrina Legal, 1992, pág. 477.

114 Así lo reconoce S. MARTIN-RETORTILLO BAQUER, El Derecho civil..., in toto; del mismo autor, «Unidad...», págs. 196 y ss. 
LEVANTAMIENTO DEL, VELO Y DERECHO ADMINISTRATIVO ...

recho administrativo privado, cuyo sentido es lograr la vinculación a Derecho. público de la actuación jurídico-privada de la Administración.

\section{EL DERECHO DE LA COMPETENCIA EN RELACIÓN CON EL PROBLEMA DE LA SUJECIÓN A DERECHO DE LA ACTIVIDAD DE LAS EMPRESAS PÚBLICAS LOCALES}

Si se sigue el criterio en virtud del cual el Derecho administrativo privado no se aplica en relación con las entidades que cumplen una simple función mercantil, gana interés el Derecho de la competencia como medio para lograr un criterio de sujeción a Derecho de las empresas que cumplan este tipo de funciones.

En principio, la sujeción al Derecho de la competencia, de la actividad mercantil de los poderes públicos, se facilita por la Ley de Defensa de la Competencia y por la Ley de competencia desleal ${ }^{115}$, considerando su indiferencia respecto de la cualidad subjetiva del ente que realiza la actividad en el mercado, ya que el criterio del cual se parte es, simplememte, el de la identificación de una «actuación que repercuta en el mercado» ${ }^{116}$. De esta forma, se consigue que la actividad de agentes tales como por ejemplo la Cruz Roja ${ }^{117}$ o los Colegios Profesionales ${ }^{118}$, o los distintos entes administrativos, quede sometida al Derecho de la competencia. Por su parte, la jurisprudencia contencioso-administrativa corrobora que «el ejercicio de la actividad económica empresarial se somete sịn excepción ni privilegio alguno directo ni indirecto a las mismas reglas de competencia que rigen el mercado" ${ }^{119}$.

Interesa la pregunta acerca de cómo el Derecho de la competencia consigue sujetar a pautas de legalidad la actividad de las empresas de las Administraciones Locales que tienen una función mercantil, ya que no es sino esto lo que interesa desde el punto de vista del Derecho administrativo.

Pues bien, respecto de este tipo de actividades, el Derecho de la competencia otorga una medida de Derecho, un criterio de legalidad. ¿Cómo? Mediante

\footnotetext{
115 Me remitiría a mi trabajo, sobre la cuestión, El Derecho administrativo privado..., págs. 331 a 360.

116 Resolución de 20 de mayo de 1994, Actualidad administrativa, n. ${ }^{\circ} 12,1995$, págs. 644 y ss.

117 Resolución del Tribunal de Defensa de la Competencia de 24 de abril de 1997; puede consultarse en la revista Actualidad administrativa, n. 44 (1977), pág. 2.963, marginal 847.

118 Véanse distintas resoluciones del TDC citadas en: S. GoNZALEZ-VARAS IBAÑEZ, La aplicación del Derecho de la competencia a los colegios profesionales, Madrid, 1997 (Edit. Tecnos).

119 Tal como dice la STS de 10 de octubre de 1989, Ar. 7352.
} 
la vinculación a principios tales como igualdad, proporcionalidad, transparencia, que se consigue cuando se aplica el Derecho de la competencia a la actividad mercantil de los poderes públicos. Esto se entiende si se considera que una empresa que no observe dichos principios incurrirá con gran probabilidad en un abuso de posición dominante, pudiéndose, por tanto declarar ilegal por esta causa la práctica realizada ${ }^{120}$.

\section{LOS CRITERIOS FUNCIONALES}

Lo que apoya la aplicación del Derecho administrativo privado es la identificación de una actividad materialmente pública (esencialmente de tipo prestacional o servicial) de la entidad correspondiente. En el Derecho español se descubre un paulatino proceso de crisis del criterio de la «forma jurídica del ente actuante» como criterio orientador del régimen jurídico aplicable ${ }^{121}$. Leyes recientes parten, en este sentido, del tipo de función realizada, para determinar o no su concreta aplicación; así, la Ley del Régimen Jurídico de las Administraciones Públicas y del Procedimiento Administrativo Común (en su artículo 2.2, «que se ejerzan potestades administrativas»), o la Ley de Contratos de las Administraciones Públicas (en el artículo 3.a: «interés general que no tengan carácter industrial o mercantil») ${ }^{122}$ y también, junto a numerosas leyes sectoriales ${ }^{123}$, la Ley 6/1997, de 14 de abril (LOFAGE), parte del tipo de función realizada, en relación con cada una de las entidades allí mencionadas, para establecer el régimen jurídico correspondiente; según esto, dicho régimen puede ser «privado» si la función es prestacional o servicial — son las llamadas «empresas públicas empresariales»-, salvo en el ejercicio de potestades admi-

120 Para un estudio de esta cuestión me remitiría a mi trabajo El Derecho administrativo privado..., págs. 285 y ss.

121 Véase especialmente J. L. MARTínez LÓPEZ-MuÑiz, «Indiferencia de la forma...», págs. 163 y ss. y J. L. MeIlÁN GiL, «La Administración Pública...», pág. 76, así como también J. M. Diaz Lema, Subvenciones..., págs. 336 y ss.; J. A. Garcla-TReVIJANo Fos, Tratado..., vol. II, págs. 329 y ss.; Jiménez dE Cisneros Cid, Los organismos..., pág. 379; J. M. SALA ARQUER, La liberalización..., pág. 112.

122 Por otra parte, la disposición adicional sexta de la Ley de Contratos exige el respeto de los principios de publicidad y concurrencia frente a las sociedades mercantiles en cuyo capital sea mayoritaria la participación directa o indirecta de la Administración o sus Organismos autónomos o entidades de Derecho público. La doctrina extiende esta regla a las sociedades mercantiles íntegramente públicas (E. GARClA DE ENTERRtA, «Ámbito de aplicación de la LC...»).

123 El criterio definidor «del ejercicio de potestades administrativas» se reitera, así, en el artículo 2 de la Ley 30/80, de 21 de junio, sobre Órganos Rectores del Banco de España; Ley 24/88, de Ordenación del Mercado de Valores; Ley 27/92, de 24 de noviembre, de Puertos del Estado y de la Marina Mercante, etc. En este contexto, puede verse, junto a R. Parada Vazquez, Régimen..., pág. 49; M. M. Fernando Pablo, la ley..., pág. 127; F. Garrido Falla y J. M. Fernández Pastrana, Régimen..., págs. 50 y ss.; R. URTASUn AMANNM, en VARIOS AUTORES, Estudios..., pág. 8. 
LEVANTAMIENTO DEL VELO Y DERECHO ADMINISTRATIVO ...

nistrativas o en la formación interna de voluntad. No está exenta, esta Ley, no obstante, de un cierto grado de confusión, porque las funciones de los organismos autónomos y de las entidades públicas empresariales son en gran medida las mismas, por lo que parece abrirse la posibilidad de crear indistintamente tanto un organismo autónomo como una entidad pública empresarial, pese a las diferencias sustanciales en cuanto al régimen jurídico. Además, el criterio seguido para afirmar la vinculación al Derecho administrativo (esencialmente, «el ejercicio de las potestades administrativas que tengan atribuidas», deja en gran medida intacta la aplicación del Derecho privado (pese a las remisiones que puedan hacerse a normas administrativas concretas como es el caso de la legislación de contratos), especialmente si uno considera que quedan en pie las leyes sectoriales que han configurado durante los últimos años un régimen de Derecho privado en relación con numerosas entidades independientes o de gestión de servicios públicos. Por eso no parece inoportuno insistir aquí en la aplicación del Derecho administrativo privado en tanto en cuanto no se logre la aplicación del Derecho administrativo respecto de las entidades cuya función es la gestión de servicios públicos.

El Derecho comunitario permite afirmar que el tipo de actuación es determinante para concretar el régimen jurídico del ente correspondiente. Si éste realiza una actividad de tipo mercantil (independientemente de su forma jurídica ${ }^{124}$ y de si forma o no parte de la Administración Pública) ${ }^{125}$ son «empresa», con la importante conclusión de su sujeción al Derecho comunitario de la competencia ${ }^{126}$. Sen-

124 La empresa será pública si, concretamente, la actividad la desarrolla una entidad que esté sometida a la influencia dominante de los poderes públicos.

125 Sentencia del Tribunal de Justicia de las Comunidades Europeas de 16 de junio de 1987, Comisión contra República Italiana; Sentencia de 16 de noviembre de 1995, Fédération française des sociétés d'assurance y otros contra Ministère de l'Agriculture et de la Pêche, asunto C-244/94; Sentencias Höfner y Elser contra Macroton y Foster y otros contra British Gas plc. de 12 de julio de 1990, asunto C-188/89, Rec., págs. $1-3.313$ y ss. (pags. 3.333 y 3350 ) y otras muchas. En la doctrina, D. SorACE, «L'ente pubblico...», pág. 369 ( «la Corte, sottolineando che intento della direttiva era quellodi distinguere chiaramente la figura deIlo Stato come pubblico potere da quella dello Stato propietario») y pág. 389 unon possibile sottrarre all'idoneo regime pubblicistico organismi cheper la posizione organizativa in cui si trovano e, conseguentemente, per le funzioni che svolgono mostrano di averesostanza pubblicistica". La doctrina considera la necesidad de acudir a los criterios funcionales o materiales: E. Malaret I García, Público..., págs. 86, 87, 101,102 y 120, baś́ndose en los artículos 75.3, 77 y 90 del Tratado de la Comunidad Europea; A. MASSERA, «Una nozione...», págs. 55 y ss., con apoyo en el Derecho comunitario; E. VALLEJo LOBETE, «Las empresas...», pág. 16.

126 Son las Sentencias del Tribunal de Justicia de las Comunidades de 20 de marzo de 1985, República Italiana contra Comisión, asunto 41/83, Rec., pág. 878; de 12 de diciembre de 1974, B. N. O. Walrave y L. J. N. Koch contra Unión Ciclista Internacional y Federación Española de Ciclismo, asunto 36/74, Rec., págs. 1.405 y ss. (pág. 1.418, apartados 4 a 10); de 23 de abril de 1991, Höfner y Elser contra Macroton, asunto C-41/90, Rec., págs. I-1.980 y ss.; igualmente la de 2 de julio de 1992, Dansk Pelsdyravlerforening (asunto T-61/89, REc., págs. II-1.931, apartados 44 y 54, págs. 1.952 y 1954); también la de 17 de febrero de 1993, Poucet y Pristre (asuntos C-159/91 y C-160/91, Rec., págs. I-637), por la que se declara que el artículo 90 no se aplica a las entidades gestoras de regímenes públicos de Seguridad Social; recientemente sentencia de 15 de enero de 1998 (asunto C-44/96). 
su contrario los entes que realicen funciones no económicas o mercantiles quedan libres de la aplicación del Derecho de la competencia ${ }^{127}$. Puede no resultar fácil el deslinde de tales funciones con aquéllas de naturaleza «empresarial» ${ }^{128} \mathrm{y}$, en la práctica, tal circunstancia puede determinarse por la presencia de «un interés público» y la ausencia de «motivaciones empresariales» ${ }^{129}$. De forma interesante, la sentencia del Tribunal de Justicia de las Comunidades, de 17 de octubre de $1989^{130}$, considera que no estamos ante «funciones públicas» cuando los «operadores económicos actúan en las mismas condiciones jurídicas que los operadores económicos privados» ${ }^{131}$.

Estos mismos criterios se descubren en las resoluciones del Tribunal español de Defensa de la Competencia. Así, por ejemplo, la sentencia de 11 de abril de 1978 parte de la identificación del tipo de actividad, para concretar entonces el régimen jurídico aplicable: «cuando la Administración, bien por sí o por medio de la empresa arrendataria de un monopolio, actúa como empresa de Derecho privado, estará sujeta a lo dispuesto en el artículo 2 de la Ley $110 / 63$ (...)» ${ }^{132}$. En este sentido, la resolución del Tribunal de Defensa de la Competencia, de 14 de enero de $1993^{133}$ declara inaplicable la Ley de Defensa de la Competen-

127 Sentencia del 20 de junio de 1996, que puede consultarse en Revista Noticias de la Unión Europea, n. ${ }^{\circ} 154,1997$, pág. 111 . Específico es, por otra parte, el planteamiento respecto de los entes gestores de servicios públicos (conforme al artículo 90.2 del Tratado).

S. Muñoz Machado, Público..., págs. 77 y ss.; J. B. Blaise y L. Idor, «Concurrence...», púg. 42; E. J. MESTMÄCKER, «Offene...», pág. 345; H. GROEBEN; J. THIESING y C. D. EHLERMANN, Kommentar..., pág. 2.545.

129 Así, la Sentencia del Tribunal de las Comunidades Europeas de 17 de febrero de 1993, Poucet y Pristre (asuntos C-159 y 160/91, Rec., págs. 1-637).

130 Ufficio distrettuale delle imposte dirette di Fiorenzuola d'Arda y otros contra Comune di Carpaneto Piacentino y otros, asuntos $231 / 87$ y $129 / 88$, Rec., págs. 3.233 y ss.

131 De ahí que, según la sentencia, han de considerarse sujetos pasivos del IVA los organismos de Derecho público en cuanto a las actividades que desarrollan en el ejercicio de sus funciones públicas cuando estas actividades puedan ser ejercidas en competencia con ellos, por particulares. Asimismo, puede verse la Sentencia del Tribunal de las Comunidades Europeas SAT contra Eurocontrol, de 19 de enero de 1994, asunto C-364/92, Rec., págs. I-43, apartado 30; para un comentario véase la revista Europe, n. 114 (marzo, 1994). Sienta aquélla que «consideradas conjuntamente las actividades de Eurocontrol, por su naturaleza, por su objeto, y por las reglas a las que se someten, consisten en el ejercicio de prerrogativas, relativas al control y polícia del espacio aéreo, que son típicamente prerrogativas públicas (de puissance publique). De ahí que no presenten carácter económico, necesario para la aplicación del Derecho de la competencia del Tratado".

132 Asimismo, puede seleccionarse la Resolución de fecha 30 de diciembre de 1993, Boletín Económico ICE, n. 2403 , del 28 de febrero al 6 de marzo de 1994: «dentro de la actividad de defensa de los intereses privados de sus miembros cabe perfectamente su actuación como agente económico (...)». «En defensa de sus intereses prịvados actúan como cualquier asociación empresarial, siendo por tanto agentes económicos equiparables a estas asociaciones».

133 Actualidad administrativa, . $^{\circ} 45,1993$, pág. 2.506. 
LEVANTAMIENTO DEL VELO Y DERECHO ADMINISTRATIVO ...

cia ya que el sujeto actúa como órgano de la Administración del Estado que ejerce las facultades que la ley le concede y que no suponen el desarrollo de una actividad empresarial. En fin, «resulta irrelevante la forma en que la Generalidad actúe en el mercado de la ITV, dado que, en cualquier caso, se trata de un operador económico sometido a las normas de competencia». Lo importante es identificar si la actuación de la Administración como sujeto es mercantil o administrativa, para afirmar el Derecho mercantil o el Derecho administrativo ${ }^{134}$.

¿Quid de los criterios funcionales? Afirman éstos la identificación de tres tipos de funciones $y$, consecuentemente, de tres niveles en la aplicación del régimen jurídico-administrativo: primero, actividades de tipo mercantil, a las que corresponde un régimen de Derecho privado ${ }^{135}$, sin perjuicio de las limitaciones jurídicas que hemos comentado, especialmente las que se derivan del propio Derecho privado respecto de su actuación ad extra; segundo, actividades administrativas prestacionales o serviciales, a las que corresponde el Derecho administrativo privado (en caso de que se pretenda hacer regir la actividad de la entidad gestora por el Derecho privado y no exista una norma que obligue a adoptar una forma jurídico-pública de gestión, que limite por tanto la «libertad de elección de la forma de gestión» que rige con carácter general) ${ }^{136}$; tercero, demás funciones administrativas (el «giro o tráfico administrativo»), a las que corresponde el Derecho administrativo.

Interesa concluir diciendo que todos estos criterios se deducen del propio Derecho administrativo, ya que en definitiva de aquél depende la medida en la que la Administración Pública puede optar por el Derecho privado y las consecuencias jurídicas que esta elección acarrea.

\section{BIBLIOGRAFÍA EMPLEADA}

R. DE ÁNGEL YÁGÜEZ, La doctrina del levantamiento del velo en la jurisprudencia, Madrid 1995.

\footnotetext{
134 Resolución del Tribunal de Defensa de la Competencia de 30 de diciembre de 1993.

135 Desde el clásico trabajo de J. L. VILLAR PALASl, «La actividad industrial...», págs. 54 y ss., hasta el más reciente de E. Garcla de Enterría y T. R. Fernández, Curso... (capítulo séptimo, donde se permite la utilización del Derecho privado cuando la Administración actúe «a un mismo nivel que los operadores económicos»). A este resultado llega también la reciente monografía sobre el tema N. DE LA SERna BILBAO, La privatización..., págs. 112 y ss. (140) y 186.

136 La aplicación plena del Derecho administrativo desde luego que sería la mejor solución. Ahora bien, ¿han de esperar estoicamente los perjudicados a que se declare inconstitucional la ley que se remite al Derecho privado? En estos casos, ha de ser posible cuando menos un control judicial conforme al Derecho administrativo privado y el levantamiento del velo, según hemos comprobado.
} 
G. ARIÑo ORTIZ, «El mercado único de la energía: los sectores del gas y la electricidad», Noticias de la Unión Europea, n. ${ }^{\circ}$ 100, 1993.

C. AsÚA, «Responsabilidad derivada de la construcción y funcionamiento de instalaciones gasistas», Revista Vasca de Administración Pública, n. ${ }^{\circ} 20,1988$.

M. BaCigaluPo SagGeSE, «Reducción y laboralización de la Función pública alemana en el marco del proceso de privatización de servicios públicos de los años noventa», Documentación Administrativa, n. ${ }^{\circ} 243,1995$.

A. Ballesteros Fernández, «La aplicación de la LCAP por los Entes locales», El Consultor de los Ayuntamientos y de los Juzgados, n. ${ }^{\circ} 17,1995$.

E. BANI, en Giusti (coordinador) y otros, Diritto pubblico dell'economia, Milani, 1994.

J. M. BAÑo LeÓN, Potestades administrativas y garantías de las empresas en el Derecho español de la competencia, Madrid, 1996.

A. BARDusco, «Servizi locali e libertà di mercato», Rivista italiana di Diritto Pubblico Comunitario, 1994, págs. 28 y 29.

J. Bermejo Vera (y Otros), Derecho administrativo. Parte especial, Madrid, 1994.

J. B. BlaISE y L. IDOT, «Concurrence», Revue trimestrielle de droit européen, $\mathrm{n} .^{\circ} 1,1995$, págs. 39 y ss.

C. Boldó Roda, Levantamiento del velo y persona jurídica en el Derecho privado español, Pamplona, 1996.

I. Borrajo InIESTA, «El intento de huir del Derecho administrativo», REDA, n. 78 (1993), pág. 233.

D. A. CARRasco Pradas, «Las agencias administrativas en Gran Bretaña, Estados Unidos y España: una aproximación comparativa», RICA, n. ${ }^{\circ}$, junio 1992.

A. Carretero, «La teoría de los actos separables», RAP, n. 61 (1970), págs. 83 y ss.

S. CASSESE, Las bases del Derecho administrativo, Madrid, 1986, traducción de L. Ortega.

F. Castillo Blanco, «Breves apuntes sobre la perfección y formalización de los contratos administrativos en la Ley 13/1995, de 18 de mayo, de Contratos de las Administraciones Públicas», El Consultor de los Ayuntamientos y de los Juzgados, n. ${ }^{\circ} 21,1995$.

F. DE CASTRo y Bravo, La persona jurídica, Madrid, 1981, pág. 21. 
LEVANTAMIENTO DEL VELO Y DERECHO ADMINISTRATIVO ...

M. F. Clavero Arévalo, Municipalización y provincialización de servicios en la Ley de Régimen Local, Madrid, 1952.

M. F. Clavero Arévalo, «Consecuencias de la concepción del Derecho administrativo como ordenamiento común y normal», Revista General de Legislación y Jurisprudencia, noviembre de 1952.

M. F. Clavero Arévalo, «El estado actual de la doctrina de los actos separables», Revista de Estudios de la Vida Local, n. ${ }^{\circ} 164$ (1969).

J. Climent Barberá, Legislación de Régimen Local, Valencia, 1987.

J. Climent BarberÁ, Nuevo Régimen Local, El Consultor de los Ayuntamientos y de los Juzgados, Madrid, 1986, pág. 752.

E. Colom Piazuelo, «Influencia de la configuración de la personalidad jurídica del municipio en la determinación de la titularidad del patrimonio local», Revista de Administración Pública, n. ${ }^{\circ}$ 137, 1995.

J. M. DE la Cuétara Martínez, La actividad de la Administración, Madrid, 1983.

J. M. DE la CuÉtARA MaRTÍNEZ y OTROS, Introducción a los servicios locales. Tipos de prestación y modalidades de gestión, Madrid, 1991.

F. Dfaz CAPMANY, «Los organismos autónomos de la Administración Local», REDA, n. ${ }^{\circ} 88$ (1995).

J. M. Díaz Lema, Subvenciones y crédito oficial en España, Madrid, 1985.

J. M. Díaz Lema, Los monopolios locales, Madrid, 1994.

J. M. Embid Irujo, «Los grupos de sociedades en el Derecho comunitario y en el español», $R C D I$, n. $^{\circ} 599$, pág. 51.

J. M. Embid Irujo, «En torno al "levantamiento del velo" una vez más. Comentario a la STS (Sala 1.a) de 20 de junio de 1991», La Ley, febrero 1992, págs. 3 y ss.

J. M. Endemaño ARóstegui, «El contrato de gestión de servicios públicos en el ámbito de la Administración local», Revista Vasca de Administración Pública, $\mathrm{n}^{\circ} 45-1,1996$.

G. FERnÁNDEZ FARREREs, La subvención: Concepto y régimen jurídico, Madrid, 1983, págs. 301 y ss.

F. J. Fernández GonzÁlez, «La Ley de contratos de las Administraciones Públicas y el contrato de servicios públicos en la Administración Local», REALA, n. 268 (1995). 
C. R. FernÁNDEZ Rodríguez, «Comentario a Serick, R., Rechtsform und Realität juristischen Personen, Tübingen 1955», $A D C, \mathrm{n} .^{\circ} \mathrm{IX}-3,1956$, págs. 975 y ss.

T. R. FERNÁNDEZ RODRÍGUEZ, «Reflexiones sobre las llamadas autoridades administrativas independientes», Administración Instrumental. Libro Homenaje a Manuel Francisco Clavero Arévalo (I), Madrid, 1994.

M. M. Fernando Pảblo, La Ley Común del Procedimiento Administrativo, Madrid, 1993.

F. FLEINER, Derecho administrativo, Barcelona-Madrid, 1993.

E. Gamero Casado, La intervención de empresas, Madrid, 1996.

E. GARCIA DE ENTERRfA, «La actividad industrial y mercantil de los municipios», Crónica del I Congreso Iberoamericano de Municipios, Madrid, 1956.

E. GaRCIA DE ENTERRÍA, «La actividad industrial y mercantil de los Municipios», $R A P$, n. ${ }^{\circ} 17$ (1955), págs. 87 y ss.

E. GaRCIA DE ENTERRÍA, «El concepto de personalidad jurídica en el Derecho público», Revista de Administración Pública, n. 129 (1992).

E. GarCla de EnTERRÍA, «Ámbito de aplicación de la LC», en GÓmEZ-FerRer (Coordinador), Comentarios a la LC, Madrid, 1996.

E. García de Enterría y T. R. Fernández Rodríguez, Curso de Derecho administrativo, Madrid, 1995.

E. GarCía Llovet, «Autoridades administrativas independientes y Estado de Derecho», RAP, n. 131 (1993).

J. A. García-Trevijano Fos, «Contratos y actos ante el Tribunal Supremo. La explotación del "Hotel Andalucía Palace" de Sevilla», RAP, n. 28 (1959), págs. 147 y ss.

J. A. García-Trevijano Fos, «Reciente evolución de la jurisprudencia administrativa: los actos administrativos admitidos por el Tribunal Supremo», $R A P$, n. $^{\circ} 36$ (1961), págs. 227 y ss.

F. GarRido Falla, «Un tema de seguridad jurídica: La regulación de los entes instrumentales», REDA, $\mathrm{n}^{\circ} 79$ (1993), pág. 391.

F. Garrido Falla y J. M. Fernández Pastrana, Régimen Jurídico y Procedimiento de las Administraciones Públicas, Madrid, 1993.

J. M. Gimeno Feliu, «Una valoración crítica sobre el procedimiento y contenido de las últimas reformas legales de contratación pública», RAP, n. ${ }^{\circ} 144,1997$.

F. GonzÁlez Navarro, Televisión pública y televisión privada, 1982. 
LEVANTAMIENTO DEL. VELO Y DERECHO ADMINISTRATIVO ...

F. Gonzalez Navarro y J. González Pérez, Régimen jurídico de las Administraciones Públicas y del Procedimiento Administrativo Común, Madrid, 1994.

S. GonZÁlez-VARAS IBÁÑEZ, El Derecho administrativo privado, Madrid, 1996.

S. González-Varas Ibáñez, El reto de los servicios públicos en Europa, Parlamento Europeo W-26, Luxemburgo, 1997.

J. L. GonzÁlez-Berenguer Urrutia, La contratación local, El Consultor de los Ayuntamientos y de los Juzgados, Madrid, 1982.

A. GuatTA, «Las otras Administraciones del Estado», Actualidad Administrativa, $1989, \mathrm{n}^{\circ} 26$.

J. M. Gutiérrez Delgado, «Últimas modificaciones legales sobre la contratación por adjudicación directa de los organismos autónomos», Actualidad Administrativa, 1991, n. 29.

H. von Groeben; J. Thiesing y C. D. Ehlermann, Kommentar zum EWGVertrag, Baden-Baden, 1991.

Jiménez de CiSneros Cid, Los organismos autónomos en el Derecho Público español. Tipología y régimen jurídico, Madrid, 1987.

J. C. Laguna de PAZ, «La renuncia de la Administración Pública al Derecho administrativo», RAP, n. ${ }^{\circ} 136$ (1995), págs. 201 y ss.

N. LONGOBARDI, «Autorités administratives indépendantes et position institutionelle de l'administration publique», Revue française de droit administratif, n. $1 / 2,1995$.

J. A. LÓPEZ Pellicer, La concesión administrativa en la esfera local, IEAL, 1976.

J. A. LÓPEZ Pellicer, «Actividades y servicios locales en el Reglamento de la Generalidad de Cataluña de 13 de junio de 1995», $R A P$, n. 141, 1996.

F. Lliset Borrell, «Las sociedades privadas de los entes locales», REALA, n. ${ }^{\text {os }} 235$ y 236 (1987) págs. 619 y ss.

F. Lliset BorRell, La actividad empresarial de los entes locales, Madrid, 1990.

F. Lliset Borrell, «Las sociedades privadas de los entes locales», Libro Homenaje al Profesor Fernando Garrido Falla, Madrid, 1992.

E. Malaret I García, Público y privado en la organización de los Juegos Olímpicos de Barcelona, Madrid, 1993.

L. Martín Rebollo, «Medio ambiente y responsabilidad de la Administración», REDA, n. ${ }^{\circ} 11,1976$. 
REALA 274-275 (MAYO-DICIEMBRE, 1997)

S. MARTín-Retortillo BAQuer, El Derecho civil en la génesis del Derecho administrativo y de sus instituciones, Sevilla, 1960.

S. Martín-Retortillo Baquer, «Unidad de jurisdicción para la Administración pública», $R A P, \mathrm{n}^{\circ} 49$ (1964), págs. 196 y ss.

S. MARTín-Retortillo BaQuer, «Las empresas públicas. Reflexiones en el momento presente», $R A P, \mathrm{n}^{\circ} 126,1991$.

S. Martín-Retortillo Baquer, «Reflexiones sobre la huida del Derecho administrativo", $R A P, \mathrm{n}^{\circ}{ }^{\circ} 140,1996$, págs. 25 y ss.

J. L. MARTíneZ LOPEZ-MuÑIz, Introducción al Derecho administrativo, Madrid, 1986, págs. 62 y ss.

J. L. MARTínez LóPEZ-MuÑIz, «Indiferencia de la forma jurídica para el concepto de empresa pública», Noticias $C E E$, n. $^{\circ} 42$, págs. 163 y ss.

A. MASSERA, «Una nozione comunitaria di pubblica amministrazione», El desenvolupament del dret administratiu europeu, Barcelona, 1993, págs. 55 y ss.

J. L. MeILÁN GıL , «La Administración Pública a partir de la Constitución de 1978», Revista Española de Derecho Constitucional, n. ${ }^{\circ}$ 47, 1996, págs. 55 y ss.

E. J. MESTMÄCKER, «Offene Märkte im System unverfälschten Wettbewerbs der Europäischen Wirtschaftsgemeinschafts, en Wirtschaftsordnung und Rechtsordnung, Festschrift für Franz Böhm, Karlsruhe, 1965, págs. 345 y ss.

J. F. Mestre Delgado, «La forma de prestación de los Servicios Públicos Locales. En particular la Concesión», en Tratado de Derecho Municipal (Tomo II), Madrid, 1988, pág. 1.227.

F. MODERnE, «L'Administration dans le débat politique en Espagne» en C. DebBasch, La Administration et politique en Europe, París, 1983.

E. Montoya MARTín, Las empresas públicas sometidas al Derecho privado, Madrid, 1996.

A. MoYa JiménEZ, La responsabilidad de los administradores de empresas insolventes, Madrid, 1997.

S. Muñoz Machado, Público y privado en el mercado europeo de la televisión, Madrid, 1993.

B. Noguera DE LA MUela, «Ente local y S.A. prevalente: experiencia italiana», $R A P, \mathrm{n}^{\circ} 141,1996$.

L. ORTEGA, «El reto dogmático del principio de eficacia», $R A P, \mathrm{n} .^{\circ} 133$ (1994), págs. 11 y ss. 
LEVANTAMIENTO DEL VELO Y DERECHO ADMINISTRATIVO ...

P. Pantaleón Prieto, «Comentario a la Sentencia de 28 de mayo de 1984», CCJC, 1984, págs. 1.711 y ss. .

R. Parada VÁzquez, Régimen Jurídico de las Administraciones Públicas y del Procedimiento Administrativo Común, Madrid, 1993.

R. Parada VÁzQuez, Derecho administrativo, vol. II, Madrid, 1995.

L. PARejo Alfonso, Eficacia y Administración. Tres estudios, Madrid, 1995.

J. Pérez Royo, El Tribunal Constitucional y división de poderes, Madrid, 1988.

L. A. Pomed SÁNCHEZ, «Fundamento y naturaleza jurídica de las Administraciones independientes», $R A P, \mathrm{n} .^{\circ} 132$ (1993).

J. PONCE SOLÉ, «Una aproximación al fenómeno privatizador en España», $R A P$, n. $^{\circ} 139$ (1996), pág. 352 y nota 30.

L. F. Prieto GonZález, Las empresas mixtas locales, Madrid, 1996.

T. Quintana LópEz, «Servicios públicos», Anuario de Gobierno local, Diputación de Barcelona, Madrid, 1996.

R. Rivero Ortega en: Revista andaluza de Administración Pública, n. ${ }^{\circ} 21$, 1995, págs. 29 y ss.

E. RIVERO YSERN, «Derecho público y Derecho privado en la organización y actividad de las empresas públicas», RAP, n..$^{\circ} 86$ (1978).

E. RIVERo Ysern, Manual de Derecho local, Sevilla, 1989.

E. RIVERO YsERN, « ¿Actos separables en los contratos de los entes públicos sometidos al Derecho privado?», Administración Instrumental. Libro Homenaje a Manuel Francisco Clavero Arévalo (I), Madrid, 1994.

P. M. Rodríguez Rosales, «La doctrina del levantamiento del velo» en $D e$ recho de Sociedades, número de Cuadernos de Derecho Judicial, Madrid, 1992, págs. 393 y ss.

F. ROMERO HERNÁNDEZ, «La empresa privada municipal y los bienes de servicio público», $R E D A, \mathrm{n} .^{\circ} 47$ (1985).

M. A. Ruiz Ferreiro, «El levantamiento del velo de las sociedades. Comentario a dos recientes sentencias del Tribunal Supremo» en Derecho de Sociedades, número de Cuadernos de Derecho Judicial, Madrid, 1992, págs. 1.044 y ss.

J. M. SAla ARQuer, «El Estado neutral. Contribución al estudio de las Administraciones independientes», $R E D A, \mathrm{n}^{\circ} 42$ (1984), págs. 401 y ss.

J. M. Sala Arquer, «Huida al Derecho Privado y huida del Derecho», $R E D A$, n. $^{\circ} 75$ (1992) págs. 399 y ss. 
REALA 274-275 (MAYO-DICIEMBRE, 1997)

J. M. SALA ARQUer, La liberalización del monopolio de petróleos en Espa$\tilde{n} a$, Madrid, 1995.

J. M. Sala ARQuer, «La empresa mixta como modo de gestión de los servicios públicos en la nueva Ley de Contratos de las Administraciones Públicas», REDA, n. ${ }^{\circ} 90,1996$.

J. SÁNCHEZ IsAC, Teoría y práctica de las concesiones de servicios locales, Barcelona, 1992.

J. A. Santamaría Pastor, Fundamentos de Derecho administrativo (I), Madrid, 1988.

S. DEL SAZ CORDERO, «La huida del Derecho administrativo: últimas manifestaciones. Aplausos y críticas», RAP, n. 133 (1994), págs. 57 y ss.

R. SERICK (traducción de J. PUIG BRUTAU), Apariencia y realidad en las sociedades mercantiles. El abuso de derecho por medio de la persona jurídica, Barcelona, 1958.

N. DE la SeRna Bilbao, La privatización en España, Madrid, 1995.

D. SORACE, «Tendencias innovadoras en la Administración Pública y el Derecho administrativo italianos», Autonomies, n. ${ }^{\circ}$ 15, 1992.

D. SORACE, «L'ente pubblico tra diritto comunitario e diritto nazionale», $R i$ vista italiana di Diritto Pubblico Comunitario, 1992, pág. 369.

F. SOSA WÁgNer, «Comentario a la desafortunada Sentencia del Tribunal Supremo de 6 de septiembre de 1989 (asunto: Empresa municipal de Barcelona "Iniciatives")", Revista del Poder Judicial, n. $19,1990$.

F. SOSA WAGNeR, La gestión de los servicios públicos locales, Madrid, 1997.

C. STARCK, Erledigung von Verwaltungsaufgaben durch Personalkörperschaften und Anstalten des öffentlichen Rechts, Baden-Baden, 1992.

V. M. Tena Piazuelo, «La empresa pública local: aspectos jurídico-formales de la gestión municipal de intereses económicos mediante sociedad anónima», REALA, $\mathrm{n}^{\text {os }} 255-256$ (1992).

E. Vallejo Lobete, «Las empresas públicas en el marco del Tratado de Roma», Gaceta jurídica de la CEE, Boletín 59, 1990.

J. L. Villar PalasI, «La actividad industrial del Estado en el Derecho administrativo», RAP, n. 3 (1950), págs. 54 y ss.

J. Wieland y J. HellermanN, «Das Verbot ausschließlicher Konzessionsverträge und die kommunale Selbstverwaltung», Deutsches Verwaltungsblatt, 1996 (8). 